\title{
MOLECULAR BIOLOGY OF HUMAN PATHOGENIC VIRUSES
}

Organizers: Peter M. Palese and Bernard Roizman

March 13-18, 1993; Lake Tahoe, California

Plenary Sessions

March 14

Entry of Viruses into Cells .2

Regulation of Gene Expression

March 15

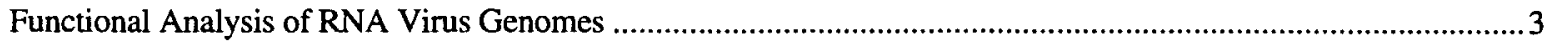

Functional Analysis of Large DNA Virus Genomes ...................................................................................

March 16

Molecular Basis of Latency. . .5

Viral Oncogenes and Transformation of Cells

March 17

Nucleic Acid Synthesis and Regulation 6

March 18

Slow Virus Infections

Late Abstracts 7

\section{Poster Sessions}

March 14

Entry of Viruses into Cells; Functional Analysis of Viral Genomes and

Gene Expression: RNA Viruses (M100-118)

March 15

Functional Analysis of Viral Genomes and Gene Expression: DNA Viruses (M200-226) 15

March 16

Retroviruses: Nucleic Acid and Packaging; Viral Structure; Slow Virus Infections (M300-320) .22

Late Abstacts .27 
Entry of Viruses into Cells

M 001 CHARACTERIZATION OF A CELLULAR RECEPTOR SPECIFIC FOR SUBGROUP A-AVIAN LEUKOSIS AND SARCOMA VIRUSES,

Kurt Zingler and John Young. Gladstone Institute of Virology and Immunology, University of California San Francisco, San Francisco General Hospital, P.O. Box 419100, San Francisco CA 94141-9100

We are studying the interactions between avian leukosis and sarcoma viruses (ALSV'S) and their cellular receptors in an attempt to better understand how retroviruses recognize and infect target cells. An avian gene that encodes a cellular receptor specific for subgroup A-ALSV was recently identified (Young, J., Bates, P., and Varmus H., submitted). Exon-trapping experiments identified those domains of this gene that encode a functional virus receptor; two different functional processed receptor genes were isolated that each encode proteins with a predicted extracellular region of only 83 amino acids. The extracellular sequences of the ALV-A receptor are highly related to each of the seven $\mathrm{N}$-terminal cysteine-rich domains of the low density lipoprotein (LDL) receptor (Bates, P., Young, J. and Varmus, H., manuscript in preparation).

In order to identify the site(s) of virus interaction on the ALV-A receptor by

mutagenesis, a synthetic ALSV-A processed receptor gene was first constructed using overlapping oligonucleotides. The important features of this synthetic gene are that it contains numerous introduced restriction enzyme sites, to facilitate mutagenesis, while the open reading frame of the processed gene is unchanged. Site-directed mutagenesis is being used to specifically alter several residues in the $\operatorname{ALSV}(\mathrm{A})$-receptor to those that are found in the corresponding positions of other LDL-receptor family members. These include Y48I, H57R, and R64S (numbered from the start methionine of the $A L V(A)$-receptor). In addition, parial characterization of this gene from two different chicken strains that are resistant to ALV(A)infection has so far revealed two amino acid differences (R71A and G72S). The effect of these, and other, mutations upon the ability of the $\operatorname{ALV}(A)$ receptor to mediate virus infection will be discussed.

\section{Regulation of Gene Expression \\ M 002 REGULATION OF TRANSCRIPTION BY COMPLEXES OF PROTEINS. Phillip A. Sharp, Thomas M. Kristie, Joel L.} Pomerantz and Jeffrey D. Parvin, Center for Cancer Research and Department of Biology, Massachusetts Institute of

Technology, Cambridge, MA 02139-4307

Initiation of transcription by RNA polymerase II requires the interaction of a number of factors. The process leading to activation of initiation by regulatory factors is not well understood. Formation of an open complex where the two strands of the promoter separate to accommodate initiation is undoubtedly an important step in the process.

Viral replication is dependent upon the regulated transcription of specific genes during the various phases of infection. In the case of a herpes simplex virus infection, transcription of the immediate early genes is induced by the viral protein $\alpha$ TIF or VP-16. This protein binds DNA in conjunction with a cellular sequence-specific DNA binding factor, the Oct-1 protein, and another cellular factor, $\mathrm{C} 1$. The Oct-1 protein is a member of the POU family which contains a homeodomain as a sequencespecific binding subdomain. Interestingly, the homeodomain ( 60 amino acids) is directly recognized by the $\alpha$ TIF protein. In fact, site-specific mutagenesis of residues on the surface of the homeodomain of Oct-1 define two $\alpha$-helices that are critical for the $\alpha$-TIF/Oct-1 interaction. This suggests that the large Oct-1 protein binds DNA in such a fashion that the DNAhomeodomain complex is available for interaction with other proteins. Oct-2, also a member of the POU family, has a homeodomain which differs from Oct-1 at seven positions. However, the Oct-2 homeodomain does not efficiently interact with $\alpha$-TIF. The identity of one amino acid at position 22 on the surface of the homeodomain is primarily responsible for this difference in activity.

The other host cell factor, $\mathrm{Cl}$, has been chromatographically purified to homogeneity. The $\mathrm{Cl}$ activity elutes as a large complex during resolution on a gel filtration column. The most purified fraction has a number of polypeptides which directly bind to the $\alpha$-TIF protein. Proteolytic cleavage patterns of these polypeptides are closely related suggesting that they share some common sequence. Several of these polypeptides are phosphorylated and treatment with phosphatase decreases their phosphorylated and treatment with phosphatase decreases the ir interaction with $\alpha \mathrm{TTF}$. Since $\alpha \mathrm{THF}$ and $\mathrm{Cl}$ associate in the of the immediate early genes of HSV is dependent upon the degree of modification of $\mathrm{C}$.

YYI IS A TRANSCRIPTIONAL REGULATORY PROTEIN WHOSE ACTIVITY CAN BE MODULATED BY THE
ADENOVIRUS PROTEIN, Brian Lewis, Anny Usheva, Ed Seto, Nobuo Horikoshi, Roberto Weinmann and Thomas Shenk, Howard Hughes Medical Institute, Department of Molecular Biology, Princeton University, Princeton, NJ 08544-1014.

YY1 is a 414 amino acid, cellular zinc-finger DNA-binding protein. It can repress transcription when bound to its recognition sequence located upstream of the initiation site within a variety of transcriptional control regions. Adenovirus E1A proteins can bind to $Y Y 1$, relieve repression and activate transcription through YY1. In addition

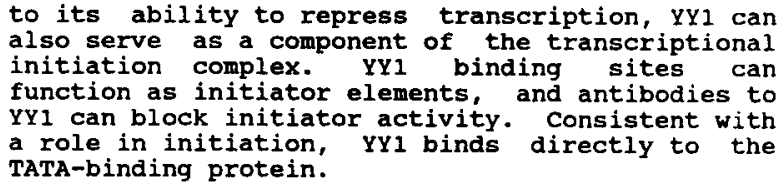
also serve as a component of the transcriptional initiation complex. YY1 binding sites can function as initiator elements, and antibodies to YY1 can block initiator activity. Consistent with a role in initiation, YY1 binds directly to the TATA-binding protein. 
M 004 ANALYSIS OF CIS AND TRANS- ACTING FACTORS IN VSV RNA REPLICATION AND VIRUS ASSEMBLY, Gail W. Wertz, Alison LeGrone, Asit Pattnaik and L. Andrew Ball, University of Alabama at Birmingham, Department of Microbiology, Birmingham, AL 35294.

Negative stranded RNA virus genomes require not only an RNA dependent RNA polymerase for infectivity but also the RNA genome itself must be encapsidated with the viral nucleocapsid protein in order to be a functional template for the polymerase. These considerations have severely hindered the application of reverse genetic methods to the analysis of cis-acting signals in regulation of gene expression of these viruses. We have carried out transcription of a complete negative stranded genomic RNA from a cDNA clone of a VSV DI RNA directly in cells simultaneously expressing the five VSV proteins from separately transfected cDNA clones. By this means, the negative stranded transcript was encapsidated with $\mathrm{N}$ protein to form a functional template and was replicated by the VSV polymerase. Furthermore, the replicated RNAs were assembled and budded to yield infectious DI virions. No helper VSV was required. Replication occured at high levels and could be assayed by direct biochemical means. An exact 3 ' terminus of the initial transcript which was generated by autolytic cleavage using a ribozyme from hepatitis delta virus was critical for replication. In contrast, up to four additional, heterologous nucleotides could be present at the $5^{\prime}$ end of the initial transcript without compromising replication. Importantly, however, these extra nucleotides were not present at the $5^{\prime}$ ends of the RNA products replicated from the initial transcript, indicating repair by the RNA polymerase either by termination of synthesis of the initial positive strand RNA prior to these nucleotides or by initiation of synthesis of the new negative strand internally, directly at the first VSV specific nucleotide. The sequences at the $3^{\prime}$ and $5^{\prime}$ termini essential for encapsidation and replication have been assayed by mutagenesis of the terminal 50 nucleotides of the DI cDNA clone with subsequent assay of the effects of these changes on efficiency of encapsidation and replication. The results of these experiments will be discussed. In addition, the minimum requirements for assembly and budding of infectious RNA-containing particles were analyzed by deletion of increasing regions of the genomic RNA. The implications of these results for virus assembly will be discussed.

Functional Analysis of RNA Virus Genomes

M 005 SOLUBLE VIRAL GLYCOPROTEIN: REGULATION DURING SYNTHESIS, SECRETION, AND IMMUNE RECOGNITION, Alice S. Huang1, Theresa L. Chang1, Michael Browning2, Steve L. Chen ${ }^{3}$, and Carol S. Reiss'1. 1New York University, New York, 10003, 2Imperial Cancer Research Fund, University of Oxford, England, and 3Children's Hospital and Harvard Medical School, Boston.

Vesicular stomatitis virus codes for one glycoprotein which is the major surface antigen of the virus. During synthesis in the rough endoplasmic reticulum, up to one-sixth of the newly synthesized glycoprotein molecules is cleaved into a carboxy terminal transmembrane anchor of about 72 amino acids and a soluble fragment containing the bulk of the extracellular domain. This soluble component called Gs is shed into the extracellular fluids. The extent of cleavage and shedding is dependent on constituents in the medium which are being identified. Gs also forms heterotrimers with the complete glycoprotein; this formation is variable depending on which viral strain is being examined. In contrast to these observations with wild-type virus, there are conditional lethal mutants which contain thermolabile glycoproteins which undergo cleavage at nonpermissive temperaures. Gs is altered so that it cannot associate with cells stably nor compete with the binding of virions to cells. It is, however, rapidly taken up by antigen presenting cells and its epitopes recognized by CD4+ cytolytic T lymphocytes in the context of class II majo histocompatibility antigens. These same lymphocytes recognize cells infected with either non-replicating defective-interfering virus particles or replication competent wild type vesicular stomatitis virus. On a molar basis, $G$ s is more efficient by $100-1000$ fold in sensitizing target cells for recognition and cytolysis by lymphocytes. Shedding of glycoproteins may be an important immunopathogenic mechanism, as well as a way to reduce interactions between virions and antibodies to the glycoprotein. Our ability to manipulate the degree of cleavage and shedding of viral glycoproteins may alter disease processes.

M 006 REPLICATION AND RECOMBINATION OF CORONAVIRUS RNA GENOME, Michael M.C. Lai, Howard Hughes Medical Institute, Department of Microbiology, University of Southern California School of Medicine, Los Angeles, CA 90033.

Coronavirus contains a $31-\mathrm{kb}$, single-stranded RNA genome, which is by far the largest viral RNA. To overcome the difficulties involved in the replication and maintenance of genetic stability of such a large RNA genome, coronavirus has developed several unique replication strategies: (1) Coronaviruses use a discontinuous transcription mechanism which fuses the leader RNA with mRNA sequences. The leader RNA sequences regulate the expression of various mRNAs, and some viral genes are differentially expressed by viruses with different leader sequences. By using an infectious cDNA vector of defective-interfering (DI) RNA, the sequence requirement of mRNA transcription is being deciphered. (2) Coronavirus undergoes a very high frequency of RNA recombination. Recombination has been demonstrated to be involved in the natural viral infection and natural evolution of viral DI RNA. Furthermore, it can rescue defective DI RNA. Recombination also occurs between the viral RNA and a nonreplicating RNA fragment transfected into cells, thus offering a new tool for genetic engineering. New data on the mechanism of RNA recombination will be presented. (3) One of the viral genes is $22-\mathrm{kb}$ long and encodes an 800-kD polyprotein, which is processed by a complex series of autoproteolytic cleavage events. These gene products are involved in the replication of viral RNA. By mutagenesis of a DI vector, the signal and mechanism of RNA replication is being understood. 
CORONAVIRUS DI RNAs: A TOOL TO STUDY REPLICATION, TRANSCRIPTION AND RECOMBINATION, Robbert G. van der Most, Raoul J. de Groot, Willem Luytjes and Willy J.M. Spaan, department of Virology, Faculty of medicine, Leiden University, PO Box 320, 2300 AH Leiden, The Netherlands.

Coronavinuses are a group of enveloped viruses that cause infections in man, other mammals and birds. The viral genome is a single-stranded $(+)$-sense RNA molecule of exceptional length. e.g. the mouse hepatitis virus (MHV) has a genome of $32 \mathrm{~kb}$. Coronaviruses have attracted attention because of their unusual replication strategy which involves leader primed transcription of subgenomic mRNAs, subgenomic-size replicative forms and homologous RNA recombination.

Homologous RNA recombination in coronavirus infected cells presumably occurs via template switching ('copv-choice'). As proposed for picomavinus RNA recombination, polymerase complexes containing nascent RNA dissociate from their original template, and re-initiate transcription on a different template. Such polymerase jumping is probably not only responsible for the high frequency homologous RNA recombination, but also for the formation of defective genomes as a result of non-homologous recombination events. and for the synthesis of leader containing subgenomic RNAs. In contrast to borh homologous recombination and defective genome formation which are not sequence specific, subgenomic mRNA synthesis can be explained as the result of a sequence-specific polymerase jump. Current data indicate that a leader RNA first binds to a sequence motif of at least 9 nucleotides (nt), the promoter, located in the intergenic regions on the negative stranded template and then re-initiates transcription. Basepaining of the leader RNA to the promoter is possible because a sequence complementary to the promoter is present near the 3 ' end of the leader RNA. Possibly, the promoter functions not only as an acceptor site for leader transcripts, but also as a polymerase recognition signal.

The high frequency homologous RNA recombination of MHV has been exploited as a means to generate defined genetic changes in the viral genome. Although a full-length infectious cDNA clone would provide the most powerful tool to study the recombination and transcription, the extreme length of the genome poses an obvious technical problem. The alternative strategy involves recombination between a synthetic DI RNA and the standard virus genome. It was shown that marker mutations introduced into the DI RNA are replaced by wild type sequences during replication in MHV infected cells. More importantly however, these mutations were incorporated into the genome of MHV-A59. The potential of DI-directed mutagenesis is illustrated by the rescue of the temperature-sensitive mutant Albany-4. These studies have also revealed that the MHV DI RNAs require a functional open reading frame (ORF) for efficient propagation, i.e. DI RNAs carrying nonsense mutations bave a strong selective disadvantage and escape mutants that have restored the ORF emerge during propagation of such DI RNAs. At present it is not known why the ORF is crucial for the fitness of an MHV DI RNA, but experiments to determine whether the DI polypeptide or translation perse is involved are in progress.

To unravel the mechanism of leader primed transcription, we have inserted a $23 \mathrm{nt}$ double-stranded oligonucleotide comprising the mRNA7 promoter into the DI cDNA clone. Transcripts from this construct contain the RNA promoter downstream of the ORF. Following RNA transfection into MHV-infected cells, this DI RNA was replicated efficiently and a $0.4 \mathrm{~kb}$ subgenomic RNA was synthesized. An extensive mutational analysis of the promoter resulted in the following observations: (i) reduction of the promoter sequence from 20 to 10 nucleotides, creating the natural mRNA3 promoter, does not significantly affect the level of subgenomic RNA, i.e. the extend of basepairing between the leader and the promoter is not the sole determinant for transcription efficiency, (ii) single nucleotide mismatches are tolerated in the $20 \mathrm{n}$ mRNA7 promoter, but not in the 10 nt. mRNA3 promoter. Furthermore, the introduction of multiple mismatches in the mRNA7 promoter allowed us to determine at which nucleotides the leader RNA is elongated after the initial priming event. A model for the leader primed transcription will be presented.

M 008 RETROVIRAL REPLICATION. Harold Varmus, Department of Microbiology and Immunology, University of Califomia, San Francisco, CA 94143-0502

I will review recent efforts in my laboratory to understand two central steps in the retrovirus life cycle: (i) integration of viral DNA into the host chromosome and (ii) synthesis of gag-pro and gag-pol fusion proteins by ribosomal frameshifting. The following topics will be considered: the use of site-directed mutants of the integrase (IN) protein of human immunodeficiency virus (HIV) to identify domains required for the activities that can now be assayed in vitro (att site processing strand transfer, disintegration, and target site selection) (1); the effects of IN mutations upon integration in vivo; the factors (DNA sequence, DNA bending, and assembly into nucleosomes) that influence the choice of integration site by IN protein and by the viral nucleoprotein complex
$(2,3)$; the cis-active determinants of the efficiency of ribosomal frameshifting on HIV and mouse mat Imary tumor virus (MMTV) RNA $(4,5)$; the structure and function of an RNA pseudoknot on the $3^{\prime}$ side of an MMTV frameshift site; and efforts to identify trans-active factors that influence frameshifting.

(1) Leavitt et al. J.Biol.Chem. in press (1993)

(2) Pryciak et al. Proc. Natl. Acad. Sci., USA, 89:9237-9241 (1992)

(3) Pryciak and Varmus, Cell 69:769-780(1992)

(4) Chamorro et al. Proc. Natl. Acad. Sci., USA 89:713-717 (1992)

(5) Parkin et al. J. Virology 66:158-192 (1992).

Functional Analysis of Large DNA Virus Genomes M 009 REGULATION AND FUNCTIONAL ANALYSIS OF EARLY, INTERMEDIATE, AND LATE GENES OF VACCINIA VIRUS, Bemard Moss, Laboratory of Viral Diseases, National Institute of Allergy and Infectious Diseases, National Institutes of Health, Bethesda, MD 20892

The 200,000 base pair linear DNA genome of vaccinia virus, the representarive member of the poxvirus family, contains about 200 genes that encode enzymes and factors for transcription and DNA replication, regulation of cell growth, protection against host defense mechanisms, and assembly and spread of infectious virus particles. The viral genes are expressed within the cytoplasm of the cell in a programmed fashion that is controlled by DNA replication and the successive synthesis of stage-specific transcription factors which recognize early, intermediate or late consensus promoter sequences. All of the proteins required for transcription of the early genes, including a multisubunit DNA-dependent RNA polymerase, transcription factors and mRNA modifying enzymes, are virus encoded and carried into the cell within the infectious virion. The translation products of the early mRNAs include a growth factor, immune defense molecules, DNA polymerase and at least two transcription factors specific for intermediate genes. Transcription of intermediate genes follows the onset of DNA replication and results in the synthesis of at least 3 transcription factors specific for late genes. Expression of the late class of genes leads to synthesis of the structural proteins as well as the early transcription factors destined to be packaged into progeny virions. Biochemical and genetic approaches have been taken to determine the roles of genes belonging to all three regulatory classes. The new methods include viral gene knockouts, use of the Escherichia coli lac repressor/operator system for viral gene regulation, replacement of viral gene promoters with bacteriophage RNA polymerase promoters, and construction of permissive cell lines that stably express viral genes. 

Rochester, New York, ${ }^{3}$ DuPont/Merck Pharmaceuticals, Wilmington, Delaware.

Human herpesvirus 6 (HHV-6) isolates can be segregated into two groups, variants $A$ and $B$, based on differences in growth properties, reactivity with monoclonal antibodies, restriction endonuclease digestion patterns, and epidemiology. The two groups share over $90 \%$ nucleotide sequence identity. HHV-6B has been etiologically associated with the common childhood disease exanthem subitum (roseola) and related illness. Both variants have been isolated from immunocompromised patients, and virus activity has been associated with illness or transplant failure. Several properties held in common between HHV-6 variants $A$ and $B$ are of particular interest in comparison with other herpesviruses.

(i) HHV-6 encodes a homolog of the adeno-associated virus type 2 rep gene 1 . The nucleic acid and amino acid sequences of this gene are over $96 \%$ identical between HHV-6A and HHV-6B. We have expressed the HHV-6B rep homolog in the baculovirus system and have begun to study its biochemical properties and pattern of expression during infection

(ii) We identified a gene encoding a homolog of the herpes simplex virus type 1 protein, UL9, that binds to the viral origin of replication and for which no homolog is present in human cytomegalovirus, a virus otherwise more closely related to HHV-
6. UL9 has two major domains, an N-terminal helicase domain and a C-terminal sequence specific $\mathrm{DNA}$ binding domain. The strongest similarity with the HHV-6 protein is in the N-terminal region. We have begun biochemical studies of the HHV-6 protein as expressed in the baculovirus system, and have identified the gene product in HHV- 6 infected cells.

(iii) Arrays of the sequence GGGTTA are present at or near the termini of the HHV -6 genome. A similar sequence is found at the telomeres of human chromosomes. The role of this sequence during HHV-6 replication is not known.

(iv) HHV.6 induces a broad stimulation of host cell protein synthesis in the absence of cell division in infected cells ${ }^{2}$. Thus the formation of the large, refractile cells commonly seen in HHV-6-infected cultures may be the consequence of an uncoupling of cytoplasmic growth from cell division.

'Thomson, BJ, Efstathiou, S, and Honess, R, Nature 351:78-80, 1991; 2Black, JB, Lopez, C, and Pellett, PE, Virus Research 22:13-23, 1992

\section{Molecular Basis of Latency}

M 011 REGULATORY PROTEINS OF HIV-1, Bryan R. Cullen, Section of Genetics and Department of Microbiology, Howard Hughes Medical Institute, Duke University Medical Center, Durham, North Carolina 27710.

HIV-1 encodes two regulatory proteins, termed Tat and Rev, that are essential for viral replication in culture. Tat is a sequence-specific transcriptional trans-activator of the HIV-1 long terminal repeat promoter while Rev is essential for the nucleocytoplasmic transport of HIV-1 mRNAs that encode the viral structural proteins. While therefore very different in their mechanism of action, both Tat and Rev directly interact with cisacting viral RNA target sites termed, respectively, TAR and RRE. In the case of Rev, a highly structured 13 nucleotide sequence located within the RRE stem-loop IIB (SLIIB) domain is both necessary and sufficient for in vitro binding by Rev. Replacement of essential sequences at the apex of the TAR RNA stem-loop with this shon RRE sequence precludes trans-activation of HIV-1 LTR dependent gene expression by Tat but permits activation by a Tat-Rev fusion protein. This in vivo trans-activation requires the integrity of the arginine-rich RNA binding domain of Rev but is independent of the leucine-rich activation motif. Interestingly, the SLIIB mediated trans-acivation of the HIV-1 LTR by Tat-Rev is efficiently squelched in trans by wild-type Tat protein. It therefore appears that Tat binds an essential cellular co-factor off the RNA, i.e. prior to interacting with TAR.

In addition to Tat, fusions of the HSV-I VP16 rans-activator with Rev also enhance HIV-1 LTR dependent gene expression when provided with the appropriate SLIIB RNA target. Therefore, DNA sequence-specific trans-activators such as VP16 can also function via a nascent RNA target. These data are consistent with the hypothesis that Tat may activate HIV-1 LTR dependent gene expression via a conventional mechanism despite its unique RNA target site.

M 012 HERPES SIMPLEX VIRUS-NEURONAL COLLABORATIONS IN THE LATENT INFECTION, Jack G. Stevens, Department of Microbiology and Immunology, UCLA School of Medicine, Los Angeles.

Herpes simplex virus is the classic example of a latent virus and we now know enough about the nature of the latent infection to discuss it in some detail. To access the nervous system so that the latent infection can be established, the virus must be neuroinvasive. Work in our laboratory over the last few years has identified viral glycoproteins of $\mathrm{gD}$ and $\mathrm{gB}$ as being important in this property. How these molecules facilitate invasiveness is currently being investigated.

The latent phase may be divided into establishment, maintenance and reactivation phases. In the establishment phase, several kinds of experiments utilizing both replicating and nonreplicating viruses have indicated that transcription from the viral genome is not a requirement for this phenomenon Indeed, except for synthesis of the latency associated transcription unit (which, in our hands, plays no role in establishment), viral transcription does not occur at this time. Similarly, viral DNA does not repticate in neurons in which the latent infection is established. Upon infection, then, a sensory neuron either expresses the viral genes associated with lytic infection and succumbs, or expresses none of these genes, survives, and is latently infected. Establishment of the latent infection. and the decisions relative to the latent and ivtic infection, are functions of the neuron
Maintenance of the latent infection appears also to be strictly a neuronal function Again, except for expression of the latency associated transcription unit, which does not contribute to this function, no viral transcripts are synthesized.

Expression from the viral genome is required for reactivation. Here, using mainty genetic analyses, we have found that some derivative of the latency associated transcription unit functions in epinephrine induced reactivation from the rabbit trigeminal ganglion. Studies designed to establish precise physical and biological properties of the transcript are in progress. 
Retroviral DNA synthesis involves two jumps or transfers of short pieces of newly synthesized DNA from one end of the viral genome to the other. The first transfer, of minus-strand primer DNA (previously called minus-strand strong stop DNA), is from the $5^{\prime}$ end of viral RNA to just before the poly(A) at the 3 end of viral RNA. The second transfer, of plus-strand primer DNA (previously called plus-strand strong stop DNA), is from the 3 end of viral DNA to the $5^{\prime}$ end of newly synthesized viral DNA. In modification of the usual model of retrovirus DNA synthesis, these transfers do not usually occur at the end of the template molecule.

Retroviral virions contain two complete copies of viral RNA held together in a dimer linkage structure. Retroviral homologous and nonhomologous recombination require formation of heterodimeric RNA and involves a switch from an RNA template to another RNA template, transfer like that of minus-strand primer DNA. Changing the dimer RNA structure by moving the encapsidation/dimerization sequence has little effect upon replication and recombination. Changing the dimer RNA by making the two copies of viral RNA different sizes causes the appearance of more reverse transcription errors.

Heterodimers of chimeric viral-cellular RNA with viral RNA also recombine, nonhomologous recombination, but at a lower rate than homologous recombination. The nonhomologous recombination is of ten at a shor region of sequence identity. When such recombination is followed by deletion, it appears there is an insertion at the site of recombination. Such insertions are frequently seen in highly oncogenic retrovinuses.

These experiments suggest that retroviral dimer RNA evolved for sex, not for replication.

Viral Oncogenes and Transformation of Cells

M 014 REGULATION OF HUMAN PAPILLOMAVIRUS LIFE CYCLE IN DIFFERENTIATING EPITHELLIUM. Laimonis A. Laimins, Dept. of Molecular Genetics and Cell Biology, University of Chicago, Chicago, II 60637.

Papillomaviruses infect cutaneous and mucosal epithellium and induce a variety of proliferative lesions in most mammals including humans. Of the 66 types of human papillomaviruses viruses that have been identified, a subset, including types $16,18,31,33$ and 51 , are associated at a high frequency with anogenital cancers. These anogenital cancers such as cervical cancer, develop from precursor lesions termed cervical intraepithelial neoplasias (CIN) which are graded from I to III depending on the disruption of the pattern of epithelial differentiation. In low grade CIN lesions, only a slight alteration of differentiation occurs and HPV DNA is found as multicopy episomes in basal cells. The production of viral particles, genome amplification, capsid protein synthesis, and virion assembly occur in a differentiation dependent manner in suprabasal cells. In carcinomas, viral DNA is usually integrated into host chromosomes, and no viral production occurs. Studies on the life cycle of human papillomavinus have been limited in the past due to an inability to duplicate the program of epithelial differentiation in vitro. Recently, my laboratory has utilized an in vitro system which allows for the stratification and differentiation of keratinocytes at the air-liquid interface of collagen raft cultures to examine the life cycle of human papillomaviruses. Using cell lines (designated CIN-612) which stably maintain episomal copies of HPV, we have been able to duplicate most aspects of the productive life cycle of HPV type, $31 \mathrm{~b}$. When CIN-612 cells were allowed to stratify in the raft cultures, tissue cross sections exhibited morphologies similar to CIN I lesions in vivo with the appearance of many koilocytic-like nuclei in suprabasal layers. In situ hybridization analysis of CIN612 raft cross sections demonstrated specific amplification of HPV31b DNA in the upper layers of differentiating cells similar to that seen in biopsies of low grade lesions in vivo. By modifying culture conditions through the addition of phorbol esters, we have recently induced the expression of capsid protein and synthesis of virions. In this system, HPV $31 \mathrm{~b}$ transcripts have been detected which are expressed constitutively throughout the stratified epithelium as well as a set of transcripts that are induced upon differentiation. This later class include transcripts for E1^E4 and late capsid genes L1 and L2. The regulation of the differentiation-dependent processes of transcription and replication will be discussed.

\section{Nucleic Acid Synthesis and Regulation}

M 015 INITIATION OF VIRUS AND CELL DNA REPLICATION, Bruce Stillman, Stephen Bell, Karen Fien, York

Marahrens, Thomas Melendy, Hai Rao, J. Michael Ruppert, Shou Waga, Cold Spring Harbor Laboratory, Cold Spring Harbor, NY 11724.

The initiation of DNA replication at virus origins of DNA replication (ori) requires a complex series of proteinDNA and protein-protein interactions. Using SV40 virus as a model system, the mechanism of initiation at the SV40 ori requires the virus encoded $T$ antigen and $a$ number of cell proteins, including replication protein $A$ (RPA) and DNA polymerase $\alpha$ /primase. SV40 $\mathrm{T}$ antigen functions as an origin recognition protein (initiator), a DNA helicase and primosome assembly protein. Studies on the initiation of SV40 DNA replication will be presented.
The initiation of DNA replication at cellular origins of DNA replication is thought to occur by a similar mechanism. We have characterized the cis-acting replicator sequences at cellular origins of DNA replication in $S$. cerevisiae and find them to be composed of multiple functional elements. A cellular initiator protein, the origin recognition complex (ORC) has been identified and is composed of six separate polypeptides. Recent studies on the ORC and cellular origins will be presented. 
Slow Virus Infections

M 016 TRANSMISSIBLE SPONGIFORM ENCEPHALOPATHIES, Bruce Chesebro, Byron Caughey, Gregory Raymond, and Richard Race, Laboratory of Persistent Viral Diseases, Rocky Mountain Laboratories, National Institute of Allergy and Infectious Diseases, Hamilton, MT 59840

Transmissible spongiform encephalopathies (TSE) are noninflammatory degenerative brain diseases which include scrapie and BSE in ruminants and rodents, and CJD, kuru, and GSS in humans. These diseases can be transmitted by ingestion or inoculation of central newous system tissues from infected individuals. The agents of transmission of these diseases are not yet definitively characterized. Although the agents usually exhibit species specificity and in some cases also variation of CNS tissue tropism within a single species, these agents appear to share common properties of relative resistance to inactivation by $\mathrm{X}$-irradiation and proteases. Early attempts to purify these agents resulted in isolation of abnormal protease-resistant form of an endogenous protease-sensitive host protein designated PrP. Protease-resistant PrP appears to be found in diseased brain tissues of all individuals afflicted with TSE and may be extensively involved in the disease pathogene sis. It remains controversial whether or not the abnormal PrP is also an integral part of the infectious agent.

Current studies have identified protease-resistant PrP in scrapie-infected mouse neuroblastoma cells. Biosynthetic experiments have shown that normal cellular $\operatorname{Pr} P$ is the precursor of the abnormal protease-resistant $\mathrm{Pr} P$, and the conversion occurs on the plasma membrane or along an endocytic pathway to the lysosomes. Recently a variety of chemical compounds known to interact with amyloid-like proteins have been shown to block new synthesis of protease-resistant PrP in vitro.

Various studies on transgenic mice indicate that expression of foreign or mutant PrP genes can alter susceptibility to TSE. To study the effect of the PrP gene on scrapie susceptibility in vitro, we have expressed foreign and mutant PrP genes in scrapie-infected and uninfected neuroblastoma cells. The results of these studies will be presented.

\section{017 GENETIC AND INFECTIOUS PRION DISEASES OF HUMANS AND ANIMALS, Stanley B. Prusiner, University of California, San Francisco}

Much evidence argues that the transmissible pathogens causing scrapie of sheep and bovine spongiform encephalopathy (BSE) of cattle as well as Creutzieldt-Jakob disease (CJD) and Gerstmann-Sträussier-Scheinker syndrome (GSS) of humans are novel and different from both viroids and viruses. Enriching tractions from Syrian hamster (SHa) brain for scrapie prion infectivity led to the discovery of the prion protein $(\operatorname{PrP})$. Determina. tion of the $N$-terminal sequence of the protease-resistant core of PrP permitted retrieval of molecular clones encoding PrP from cDNA libraries. The finding of PrP mRNA in uninfected tissues led to discovery of the cellular PrP isoform denoted PrPC and the abnormal PrP isoform designated PrPSc Four lines of transgenic ( $\mathrm{Tg}$ ) mice expressing both $\mathrm{SHa}$ and mouse (Mo) PrP genes exhibited distinct incubation times after SHa prion inoculation, which were inversely correlated with the steady-state levels of SHaPrP mRNA and SHaPrPC. Tg mice inoculated with SHa prions had $-10^{9} I_{50}$ units of SHa prions per gram of brain while $<10$ units of Mo prions were found. Conversely. Tg mice inoculated with Mo prions had $\sim 10^{6} \mathrm{ID}_{50}$ units of Mo prions and $<10$ units of $\mathrm{SHa}$ prions. These results argue that the species barrier for scrapie prions resides in the primary structure of PrP and forma. tion of infectious prions is initiated by a species-specific interaction between $\mathrm{PrPSC}$ in the inoculum and homologous $\mathrm{PrPC}$. Ataxic GSS in families shows genetic linkage to a mutation in the PrP gene leading to the substitution of Leu for Pro at codon 102. Tg mice expressing MoPrP with the GSS point mutation spontaneously develop neurologic dysfunction, spongiform degeneration and astrocytic gliosis. Inoculation of brain extracts prepared from these $\mathrm{Tg}$ (GSSMoPrP) mice into Syrian hamsters and $\mathrm{Tg}$ mice has produced neurodegeneration in recipient animals after prolonged incubation times. If convincing data on serial passage of prions from the inoculated recipients can be obtained, then these results will argue that prions are devoid of foreign nucleic acid. Pulse-chase radiolabeling experiments of scrapie-infected cultures of mouse neuroblastoma cells indicate that protease-resistant PrPSc is synthesized during the chase period with $t_{1 / 2}-1-3 \mathrm{~h}$ from a proteasesensitive precursor, consistent with the conclusion that $\mathrm{PrPC}^{\mathrm{C}}$ and $\mathrm{PrPSC}$ differ due to a posttranslational event. The acquisition of PrP protease resistance in scrapie-infected cultured cells was found to be independent of Asn-linked glycosylation. $\operatorname{Pr} \mathrm{PC}^{\mathrm{C}}$ is bound to external surface of cells by a glycoinositol phospholipid anchor. In contrast, PrPSc accumulates within cytoplasmic vesicles of cultured cells. Attempts to demonstrate a scrapie-specific nucleic acid within highly purified preparations of prions have been unrewarding to date. These observations are in accord with many unsuccessful attempts to inactivate prion infectivity by procedures that specifically hydrolyze or modify nucleic acids. Although it seems likely that transmissible prions are composed only of PrPSe molecules, a hypothetical second component such as a small polynucleotide remains a formal possibility. Studies on the structure of $\mathrm{PrPSc}$ and $\mathrm{PrPC}$ have been unsuccessful in defining a posttranslational chemical modification that distinguishes one $\mathrm{PrP}$ isoform from the other. Distinct prion isolates or "strains" produce different patterns of PrPSc accumulation. Whether distinct prion isolates result from multiple conformers of $\mathrm{PrPSc}$ or they arise from differences in Asn-linked oligosaccharides is unknown. The study of prion diseases seems to be emerging as a unique area of investigation at the interface of such disciplines as genetics, cell biology and virology.

\section{Late Abstracts}

EFFECT OF GENETIC DIVERSITY ON THE FUNCTION OF HIV-1 PROTEASE Susan Richardson, Isobel Brooks, Jeffrey Stebbins, Ingrid Deckman, René Morris, and Christine Debouck, Department of Molecular Genetics, Biopharmaceutical R\&D, SmithKline Beecham Pharmaceuticals, King of Prussia, PA 19406.

Like all retrovinuses HIV-1 produces a small, dimeric aspartyl protease which specifically cleaves the gag and gag-pol polyprotein precursors encoding the structural proteins and enzymes of the virus. This proteolytic activity is absolutely required for the production of mature, infectious virions and is therefore an attractive target for therapeutic intervention. Multidisciplinary efforts have led to the identification of specific inhibitors of this critical viral enzyme. The recent emergence of genetic variants of HIV-I exhibiting resistance to various inhibitors of reverse transcriptase has raised questions about the possible emergence of resistance to inhibitors of other retroviral functions such as the protease. Although the ultimate answer will come from the clinic, one can begin to address this question by examining the effect of natural genetic variation on the protease activity and its sensitivity to inhibitors.

In one approach, we have examined the natural genetic variation in the protease from several clinical isolates of HIV-1 obtained from Europe

and North America. The protease coding region from 6 Dutch and 13 US HIV-1 isolates was rescued by PCR and shown by nucleotide sequencing to contain between 1 and 7 amino acid substitutions within the 99 residues of the mature protease as compared to the laboratory strain $\mathrm{BH} 10$.

In a second approach, we have compared the enzymatic properties of the HIV-1 and SIV proteases and found that these enzymes are very similar with respect to their activity towards several peptide substrates and their sensitivity to most inhibitors. Remarkable exceptions include the inability of SIV protease to cleave the Phe*Tyr bond found in HIV-1 reverse transcriptase and its relative resistance to selected inhibitors. We are now working on the identification of the amino acid residues that are responsible for the differences observed between these two retroviral enzymes.

Supported in part by NIH grant GM39526. 
REPIJCATION AND PERSISTENCE OF HEPATITS B VIRUSES, Dos Ganem, HFad and Deperumeat of Microbiology and Meticine, University of Californiz, Sm Francisco, CA $94143-0502$

Replication of bepatitis B viruses proceeds by reverse unnscription of an RNA intermediate, a rection canlyzed by the vinus-encoded polymerase (P protein). The reaction product is a partially dapiex DNA whose minus strand is coralently linked to the $P$ procein. Several lines of evidence have previously subsested thet functional reverse transcripuse may require the presence of other viral products. notably the macleocapsid protein for activity. We have expressed enzymatically active $P$ protein in recombinant yeas cells, using retrotransposon Ty as a vector. Remarkably, the enayme initives correctly on viral RNA in yest cells in vivo, producing nascent DNA chains covalently linked to provein, exactly as found in vinus-infected cells. Replication complexes isolated from these yeast are enzymatically active in vitro, incorporating deoxynucleoside triphosphates into DNA in a reaction that is actinomacin D-resistant but sensitive to RNase pretrentment. These resules indicate that, coatrary to expectation. $P$ protein is the sole viral proxein roquired for the correct prining of rove trnscription, and esoblish a tractoble system for the biochemical dissection of the reaction and for the sereening of inhibitors with entivinl powential.

Persistent HBV infectican requices mointenance in the nucleus of a pool of episomal, monomeric closed circular DNA to serve as the uranseriptional template. This pool is mintained by recycling of cytoplasmic products of reverse transcription to the nucleus. Treatment of cells with microbubalodisnuping agents leads to a prompt inhibition of viral replication, raising the possibility that cytoplasmicto-nuclear unafic of vinl nucleocapsids may involve microtubeledeperdent matility systems.

THE MECHANISM OF PARAMYXOVIRUS P GENE MRNA EDITING. Daniel Kolakofвky, Jean-philippe Jacques, Sylvie Rochat. Dept. of Microbiology, Univerity of Geneva, Switzerland. Almost all paramyxoviruses modify their $P$ gene
mRNAs by $G$ insertions during synthesis, to create franeshifts which fuse downstrean overlapping DR7s to an N-terminal portion of the gene. This process is referred to as mRis editing. Different viruses have different editing. Dicterent viruses to editing patterns which appear to be matched to thelr oR expression requirements. For example, sendai and beasles virus predominantiy insert a single $G$ to acsess the $V$ onp, bPIV3 inserts 1 to 6 Gs at equal frequency to accesss both the $y$ and $D$ ORTA, and SVS and mumps virus predominantly ingert $2 G s$ to access the $c-$ terminal portion of the $P$ ORF.

Based on editing site sequence comparisons, and aruh oynthesis experinents in vitro in which the NrPs vere varied, a stuttering nodel has been proposed for this form of editing. For sendai virus, where the $G$ is inserted opposite a cun of $3 \mathrm{Cs}$ on the template ve propose that the transcriptase would pause after copying the transcriptase would pause after copying the ing 1 base ctill carryisg che j'end of the nascent chain. When synthesie resumes, one $G$ will be inserted as the niddle template $C$ will now be copied twice. For bPIV3, the slippage-insertion will be repeated 1 to 6 tires. Since SRN and bPIV3 use suggests that the difference is due to counting mechanism which determines the number of slippage-insertion events. For SV5 and munps vizus, a 1 base slippage is disfavored because an A:C pair yould be formed in the nis-alignment injernediate, whereas a 2 hase slippage only 0:G pairs; hence a 2 base slippage is then the predominant event.

the predominant event. To test this model, we have made a DMA plasmid which expresses a SEN mini-genome which itself is designed to express a mini-mpus containing the editing site. The 5 , end of the wini-genome is defined by a T7 promoter and the 3'end by $a$ rijozyme. Viral encapsidation and expression of the mini-genome is provided via cloned and $T 7-$ promoted NP, $P$, and $L$ genes, and $T 7$ polymerase via a recombinant vaccinia virus. One construct, containing $103 \mathrm{nt}$ of the $P$ gene, vas found to produce nini-mRNAs wich were edited identically to those in a natural infection (50z of the containing a IG insertion $2 G$ insertions representing $<5$ insertion, $2 G$ insertions experiments in of the mRAMs). Results of experine sequence at the insertion site were altered by point uutations, ani by substituting the editing regions of numps virus and bPIV3 for that of sEM, will be basically the sane editing sequence, this

REPLICATION AND RECOMBINATION OF HERPES SIMPLEX VIRUS DNA, Robert Lehmm, Paul Boehmer, Mark Dodson, Thomas Hemandez Byong Doo Song. Karen Kelly, Rebecen Dutch, Robert Bruckner and Boris Zemelmm. Department of Biochemistry, Beckman Center, Stanford University, Stanford, CA $94305-5307$

We have chosen the linear $153 \mathrm{~kb}$ genome of herpes simplex 1 virus (HSV-1) as a model for the replication and recombination of eukaryotic chromosome.

The products of seven HSV-1 enes are necessary for HSV-1 DNA replication in vivo. These proteins, which have been obtained in near homogeneous form, include a DNA helicase that binds specifically to an HSV-1 origin, a heterotrimeric helicase-primase, a DNA polymerase with its associated processivity enhancing factor and single-stranded DNA binding protein. Our recent malyses of these enzymes will be presented as will our atrempts to reconstirute replication of HSV-1 origin containing

plasmids in vitro. that medistes recombination between repeated copies of the 317 base pair
HSV-I a sequence. Recombination leads to deletion of a lacZ indicator gene sinured between two directly repeated copies of the a sequence, and is scored by transfommation of lacZ- Escherichia coli. The two products of the reaction can be abserved directly by Southern analysis and by primer extension reactions. The recombinase activity is also detectable, but at a lower level in uninfected cell extracts. The DNA substrate must contain the two a sequences arranged in direct orientation to generate the lac $Z$ deletion. When the sequences are arranged in inverted orientation, an inversion results. A substrate with two homologous sequences of size and GC content similar to the a sequence undergoes recombination at a much lower frequency. The reaction requires a divalent cation $\left(\mathrm{Mg}^{2+} \circ \mathrm{Mn}^{2+)}\right.$, but not ATP or any other nucleoside triphosphate. 
THE INTERFERON-INDUCED, RNA-DEPENDENT PROTEIN KINASE, Charles E. Samuel, Steven McCormack, and Daniel C. Thomis, Dept. of Biological Sciences, University of Califormia, Santa Barbara, CA. 93106 The RNA-dependent P1/eIF-2 $\alpha$ protein kinase (PKR) is an interferon-induced, cAMP-independent proteinserine/threonine kinase. The PKR kinase activity responsible for the phosphorylation of protein synthesis initiation factor eIF- $2 \alpha$ is a property of the IFN-induced protein P1. The cDNA structure of $P 1$ has been elucidated and molecular cDNA clones have been expressed, thereby permitting the identification of the RNA-binding domains and the catalytic domains of PKR. The expression of wild-type P1 KIN cDNA, which encodes an active PKR protein kinase, was compared with that of the phosphotransfer catalytic domain II K296R mutant cDNA which does not encode an active kinase, and with that of RNA binding domain mutants which do not bind activator (reovirus sI mRNA, HIV TAR RNA) or inhibitor (adenovinus VA RNA, HIV TAR RNA) viral RNA molecules. The results indicate that the amount of active PKR kinase protein present in a cell is regulated at the transcriptional level by interferon; at the translational level by an autoregulatory mechanism dependent upon the catalytic activity of the kinase and at the post-translational level by virus-encoded activators and inhibitors. Both activator and inhibitor RNAs bind to the same motif of the PKR kinase, a motif which is present in several different RNA binding proteins of viral and cellular origin. The IFN-induced, RNA-dependent PKR protein kinase appears to play a central role in the antiviral action of interferon against a wide range of animal viruses; it may also be an important component of the cell growth inhibitory response induced by interferons.

HIV REVERSE TRANSCRIPTASE: STRUCTURE AND SPECIFICITY FOR tRNA, Thomas A. Steitz, Lori A. Kohlstaedt, Jimin

Wang, Phoebe A. Rice, David Boisvert and Jonathan M. Friedman, Department of Molecular Biophysics and Biochemistry and Chemistry, Howard Hughes Medical Institute, Yale University, New Haven, CT 06511.

The structure of HIV reverse transcriptase (RT) co-crystallized with a non-competitive inhibitor, Nevirapine, has been determined at 3.2 $\dot{A}$ resolution. The heterodimeric p66/p51 molecule shows an asymmetric structure. The polymerase domain of the 66 kilodalton subunit has a large cleft and resembles a right hand, while the p51 subunit shows no such cleft. One of the four polymerase subdomains at the base of the cleft has the same structure and conserved catalytic residues as the Klenow fragment suggesting that the catalytic subdomains of polvmerases evolved from a common precursor. A-form RNA-DNA hybrid can be model built into the deep cleft that extends between the polymerase and RNase $\mathrm{H}$ active sites, placing the 3' end of the primer strand next to the conserved polymerase active site carboxyls and the template strand 20 residues upstream next to the RNase $\mathrm{H}$ active site metal ions. Nevirapine binds in a pocket adjacent to the DNA and at the base of a "thumblike" protrusion. Mutations in RT that are resistant to Nevirapine have altered protein side-chains contacting the inhibitor. It is hypothesized that this non-competitive inhibitor prevents polymerization by preventing DNA-induced motion of the thumblike protrusion. RT side-chains whose mutation reduces the sensitivity of RT to AZT and DDI appear to be largely in contact with the model-built template strand of an RNA-DNA hybrid substrate. Surprisingly, interactions between the protein and the template appear to be important in the enzyme's ability to discriminate against these deoxynucleoside triphosphate analogues. HIV RT can use either tRNA ${ }_{3}^{\text {Lys }}$ or tRNA ${ }_{2}^{\text {Gln }}$ as primer for DNA synthesis in vitro without the addition of any other host or viral proteins. $\underline{\underline{E}}$. coli tRNA ${ }_{2}{ }^{\mathrm{Gln}}$ can serve as primer for HIV $\mathrm{RT}$ if the primer binding site sequence is both complementary to 18 nucleotides at the 3' end of $\mathrm{RNA}_{2}$ Gin and is at the 3 ' end of the template. If an 8 nucleotide viral sequence 3 ' to the primer binding site is included in the template, tRNA $_{3}$ Lys continues to prime synthesis while $t \mathrm{RNA}_{2}{ }^{\mathrm{Gln}}$ fails to prime synthesis from a template whose primer binding site is complementary to tRNA ${ }^{\mathrm{Gla}}$. This 8 nucleotide template sequence that is adjacent to the primer binding site contains a 6 nucleotide sequence that is complementary to the anticodon loop of human $\mathrm{RNNA}_{3}{ }^{\mathrm{Lys}}$ implying that the anticodon loop of $t R N A^{\text {Lys }}$ may be base-paired to it. Changing this sequence 3 ' to the primer binding site to be complementary to the anticodon of tRNA ${ }^{\mathrm{Gin}}$ restores tRNA ${ }^{\mathrm{Gln}}$ primed synthesis, consistent with a direct anticodon-template interaction.

IRES-CONTROLLED PROTEIN SYNTHESIS, GENOME REPLICATION, AND CELL-FREE, DE NOVO SYNTHESIS OF POLIOVIRUS, Eckard Wimmer ${ }^{\top}$, Akhteruzzaman Molla', Christopher Hellen', Aniko Paul', Gary Witherell', Michael Schmid', Tatjana Pestova', Sung Hoon Shin', Luis Alexander', Hui Hua Lu', Kevin Harris', Caroline Mirzayan', Juan Lama', Xui Mei Cao', and Anna Gil', 'State University of New York at Stony Brook, Stony Brook, NY, ${ }^{2}$ Massachusetts Institute of Technology, Cambridge, MA

After entry into the cytoplasm, the single-stranded RNA genome of poliovirus serves as mRNA and subsequently as template for RNA genome replication. Initiation of virus-specific translation is controlled by the "internal ribosomal entry site" (IRES), a 400 nt-long segment within the 5 'non-translated region ( $5^{\prime}$ NTR). The IRES, a cis-acting element found in ail picornavirus genomes, directs cap-and 5 'end-independent protein synthesis, a process that, remarkably, involves the nuclear polvpyrimidine track binding protein (DPTB) as an essential trans-acting factor. With the use of the IRES element of encephalomyocarditis virus (EMCV), we have constructed dicistronic, viable polioviruses one of which has the genotype [PV]5'NTR-P1. [EMCV]IRES-[PV]P2-P3-3'NTR. Dicistronic polioviruses have not only provided proof for the in vivo function of IRES elements, but they have also allowed us to dissect genetically the poliovirus polyprotein (PP) and the poliovirus 5'NTR. Moreover, the blueprint of the dicistronic poliovirus described above has led us to construct novel expression vectors where a foreign gene has been inserted into the poliovirus genome.

Genetic austerity dictated RNA viruses to compress genetic information. As a consequence, a poliovirus-specific protein, or even its polypeptide precursor, may have different functions. We will discuss as examples $2 A^{* 0}$ and $3 C D^{\circ 00}$, two proteinases. $3 C D^{\circ \times 0}$ is (i) the precursor for proteinase $3 C^{\circ \%}$ and RNA polymerase 3D ${ }^{\text {pal }}$, (ii) the enzyme responsible for cleaving the capsid precursor P1, (iii) possibly involved in RNA replication, even though it has no polymerase activity. Purified poliovirus polypeptides $3 C^{\text {mero }}$ (a mutant impaired in self-cleavage), $3 D^{\mathrm{pod}}, 3 A B$ (the presumed precursor for the genome-linked protein $\mathrm{VPg}$ ). and $2 C$ have allowed us to study poliovirus RNA synthesis in a reconstituted system. We will also present evidence suggesting that polypeptide $2 \mathrm{C}$, the protein to which guanidine resistance of poliovirus maps, is an ATPase with RNA helicase activity.

We have discovered that incubation of plasmid-transcribed, full-length poliovirus RNA in a non-infected HeLa cell extract leads to virus-specific translation, proteolytic processing, genome replication, and formation of infectious poliovirus. The cell-free, de novo synthesis of poliovirus, a process that has not been achieved with any virus before, has allowed us to study the role of membranes, and the mechanism by which drugs interfere with viral proliferation. 
Entry of Viruses into Cells; Functional Analysis of Viral

Genomes and Gene Expression: RNA Viruses

M 100 MRNA TRANSCRIPTION AND NUCLEOTIDE SEQUENCE ANALYSIS OF MUMPS VIRUS VACCINE AND VARIOUS OTHER STRAINS.

M.A.Afzal'; A.R.Pickford'; R.P.Yeo ; B.K.Rima ${ }^{2}$; M.L.Bentley'; T.Forsey' and P.D.Minor'. 1- National Institute for Biological standards and control, South Mimms, Potters Bar, Herts, U.K. 2- Division of Genetic Engineering, The Queen's University of Belfast, BT9 7BL, Northern Ireland, U.K.

mRNA transcription of two currently used mumps virus vaccine strains, namely the Urabe and Jeryl Lynn strain, is compared with other mumps virus strains. The Jeryl Lynn strain unadapted to Vero cells produces monocistronic mRNA transcripts of all the genes examined while a similar urabe strain lacks detectable monocistronic transcripts of the SH gene. Similarly the expression levels of the $F$ gene are also low. Surprisingly, most of the wild types strains also produce less mRNA transcripts of the SH gene, although $M-F, F, S H-H N$ and HN genes specific transcripts are present almost in equimolar amounts. SH mRNA in Urabe infected vero cells becomes detectable after several passages. Moreover, aberrant mRNA transcripts of various lengths specific for the $N$, $M, F, S H$ and $H N$ genes, are also identified in the transcriptional products of various wild type mumps viruses. No aberrant transcripts for the $P$ gene of mumps virus have been identified yet. Further analysis of total and poly A RNA shows that aberrant transcripts are possibly polyadenylated at their 3'ends. Nucleotide sequence analysis of the cDNA fragments amplified by $P C R$ of the $M, S H$ and the HN genes of vaccine viruses reveals that MMR vaccines based on the Urabe mumps component are homogeneous in virus population while that of the Jeryl Lynn vaccine is not. The probable origin of the two variants identified in the Jeryl Lynn vaccine will also be discussed.

M 102 RESCUE OF SYNTHETIC ANALOGS OF GENOMIC RNA OF RESPIRATORY SYNCYTIAL VIRUS AND PARAINFLUENZA VIRUS TYPE 3, P. Collins, K. Dimock, M. Mink, D. Stec, L. Kuo and H. Grosfeld, Laboratory of Infectious Diseases, Building 7, Room 100, NIAID, NIH, Bethesda, MD 20892

Respiratory syncytial virus (RSV) and parainfluenza virus type 3 (PIV3) are the two most important agents of pediatric respiratory tract disease worldwide and represent two distinct lineages within the paramyxovirus family. cDNAs were constructed to encode truncated synthetic genomic RNA analogs in which all of the viral genes were removed and replaced by an expression cassette. This cassette consisted of the bacterial chloramphenicol acetyl transferase (CAT) gene flanked by short conserved RSV or PIV 3 sequences that were presumed to be transcription signals. Run-off RNA synthesis in vitro by $\mathrm{T} 7$ polymerase yielded negative- or positive-sense RNA analogs (mimicking virion or replicative intermediate RNA, respectively) containing the exact, correct genomic RNA termini. When transfected into tissue culture cells and complemented by superinfection with the homologous standard virus (RSV or PIV3), each RNA analog was "rescued" as evidenced by the intracellular expression of CAT and by the production of infectious particles which could be passed multiple times onto fresh cells (in the presence of helper virus). In the case of PIV3, expression of CAT increased 3000 -fold during serial passage. The RSV-CAT RNA was shown to encode a subgenomic polyadenylated mRNA, providing evidence that the presumed transcription signals indeed function in that capacity. These data showed that (i) the minimum sequences required for encapsidation, transcription, replication and packaging into virions are contained within the VRNA termini, and (ii) these sequences could be attached to a foreign gene without loss of function, indicative of an amenability to engineering. For each virus, the $c i s$-acting sequences in the leader-containing terminal segment are being mapped by (i) the insertion of single dinucleotides or hexanucleotides at various locations, and (ii) saturation mutagenesis wherein each sequence position is being changed systematically to all possibilities. Other studies have been performed involving deletions and extensions on the $3^{\prime}$ end, $5^{\prime}$ end, and within the RNA analog. Results to date indicate that RSV and PIV 3 have differences in the organization of cis-acting signals in the leadercontaining end of genomic RNA. Other constructs have been made to analyze transcription signals and intergenic regions. Successful rescue and passage was achieved for an RSV virion RNA analog that is $49.3 \%$ of full parental length.
M 101 THE ROLE OF WFIUENZA MATRX PROTEN IN

VIRUS PARTICLE FORMATION, Roy $T$. Avalos, and Debi P. Nayak. Department of Microbiology and Immunology, UCLA School of Medicine, Los Angeles, Ca 90025 .

Influenza A virus is a canerber of the unhumy ouvirus family and is Influenza A virus is a enetnber of the onhoury xovirus family and is composed of a lipoprotein envelope surpending gight nezative stranded RNP segments. The viral envelope is composed of a lipid bilayer,
derived from the host plasma membrane and contains two derived from the host plasma membrane and contains two (NA) and a norglycosylated transmembrane protein (M2). During the process of replication nueleocapsids are symthesized within the nucleus. Concurrently envelope proteins are rynthesized within the endopiasmic reticulum, and uransported along the exocytic pathway to the plasma membranc.

In order to initiate particle formation newly syathesized nucleacapsids must be expored from the nueleus inw the cywoplaso and interati with the envelope cormunents. Currently it is thougha that the Matrix $\left(M_{1}\right)$ proteio mediates this process by interseting whith the viral glycoproteins and the nucleocapsids. The aim of the project is wo define the assoxizations whith (xcur during viral assembly. We have exarined BHK and MDBK cells infected with the ANSN/33 strin of influenza $A$ vinus. At ostly time periods post infection we bave observed thar $M$ protein was not membrane associaled, and at later time periods $M$ was found to he nembrane-assoxiated. Expression of $M$ protein alone shows that jt docs not becotne membrane-2ssociated. This result suggests that $M$ protein alone cannot becoroe membraneassuciated. It order to investigate the specificity of membrane interactions we are currently cxpressing the $M$ protcin and the interactions we are currently cxprcssing the $M$ protcjn and the
glycoproteins (HA and NA) in various combinations. These results gillt be presented.
M 103 ANTIVIRAL SENSITIVITY OF COXSACKIEVIRUS B3 (CB3) IS DEPENDENT ON CELL TYPE - ROLE OF RECEPTOR AFYINITY?, Frank J. Dutko, M. Pat Fox, Maureen G. Woods, Alix A. Erenberg, Mark A. Mckinlay and Daniel C. Pevear, Department of Virology, Sterling winthrop pharmaceuticals Research Division, Rensselaer, NY 12144

We compared the replication of CB3 in HeLa and MK (monkey kidney; LLC-MK2) cells. Virus preparations made in either cell type produced 100-fold more plaques on Hela cells than MK celis, and the plaques on either cell type were shown to be CB3 by serum neutralization. Surprisingly, CB3 replication in HeLa cells was resistant (minimal inhibitory concentrations of $\succeq 3 \mu \mathrm{M}$ ) to capsidbinding WIN compounds (such as WIN 54954) that inhibit adsorption and/or uncoating of rhinoviruses and polioviruses, whereas $\mathrm{CB} 3$ replication in MK cells was inhibited by the compounds at concentrations of 0.02 to $0.003 \mu \mathrm{M}$. The compounds had no effect on the adsorption of CB3 to HeLa or MK cells. Thus, we hypothesize that the WIN compounds inhibit uncoating in MK cells but not in Hela cells. In the adsorption studies, we also found that the binding affinity of CB3 for Hela cells was approximately 7-fold higher than that for MK cells suggesting that the high affinity interaction of $\mathrm{CB} 3$ with HeLa cell receptors induces a different conformational change in the virion compared to that induced by the MK receptors, and the conformational changes induced by HeLa receptors cause the compounds to exit the drug binding pocket in VPI of the virion. Experiments with [3H]-WIN compounds and CB3 are underway to test this hypothesis by determining whether WIN compounds remain bound in CB3 after the virus adsorbs to $M K$ cell receptors (and thus the compounds are able to inhibit viral uncoating), but exit the pocket after CB 3 binds to Hela cells. An alternative hypothesis which is also being examined is that these results are due to different viral variants. 
M 104 A CELL LINE DEFECTIVE IN HERPES SIMPLEX VIRUS ENTRY HAS FUNCTIONAL LEVEIS OF HEPARAN SULFATE, A. Oveta Fuller, G. Subramanian, Deborah McClain, Wen-Chi Lee and Aleida Perex, Department of Microbiology and Immunology, University of Michigan Medical School, Ann Arbor, MI 48109-0620

Herpes simplex virus (HSV) entry involves several types of attachment that trigger virus fusion with the plasma membrane at neutral $\mathrm{pH}$. We have identified and characterized cells that consistently produce four logs lower yields of HSV than HEL or HEp-2 cells due to a defect in entry. On the defective cells, radiolabeled virus binding is significantly reduced. Virus proteins are not synthesized indicating lack of penetration and uncoating. Transfection of HSV genomic DNA to bypass the normal entry process produces similar yields of infectious virus from HEp-2, HEL and the low susceptible cells. Therefore, all these cells can support the HSV replicative cycle. Biochemical analyses of heparan sulfate (HS), a glucosaminoglycan known to be important for HSV entry, revealed similar amounts and sulfation patterns on HEL, HEp-2 and low susceptible cells. This suggests that some other component is lacking, and is consistent with evidence from virus blocking experiments that HSV requires a saturable non-heparin-like receptor for infectious entry. Sodium chlorate treatment, which prevents sulfation of cell surface components, reduces virus yields from $10^{8}$ on HEL and HEp-2 cells to approximately $10^{6}$, and from $10^{4}$ on the low susceptible cells to nearly undetectable levels. These results suggest that lack of sulfated proteoglycans substantially decreases, but does not completely abolish, production of infectious virus from highly susceptible cells which normally have both types of receptors. In contrast, for the cells that are defective in entry, absence of both the sulfated proteoglycans and the second receptor abolishes entry and virus production. Based on the above findings, we conclude the following. The cascade of events in HSV entry includes attachment to at least two types of cell surface components. Heparan sulfate is important, but not sufficient, for efficient HSV entry. A second non-heparin-like receptor is low, or lacking, on the low susceptible cells. Moreover, the low susceptible cells provide a critical tool to identify and isolate the second HSV receptor and understand its role in entry, infection and tropism of this common human pathogen.

\section{106 PATHOGENICITY OF COXSACKIE A AND B VRUSES IN A MOUSE} MODEL, Timo Hyypiä ${ }^{*}$, Markku Kallajoki ${ }^{2}$. Glyn Stanway ${ }^{3}$, Reinhard Kandolf 4 , and Hannu Kalimo ${ }^{2}$, Departments of Virology 1 and Pathology 2 , University of Turku, SF-20520 Turku, Finland, Department of Biology 3 , University of Essex, Wivenhoe Park, Colchester $\mathrm{CO} 4$ 3SQ, England, and Max-Planck-institut für Biochemie 4 , D-8033 Martinsried, Federal Republic of Germany. Coxsackieviruses are divided into $A$ and $B$ subgroups on the basis of their pathogenicity in newborn mice. Although used in the classification of these viruses our understanding of the details of the infection is incomplete due to the lack of sensitive and specific techniques to localize the viruses in affected tissue. We have used in situ hybridization to detect coxsackievirus genomes in tissues of newborn mice after infection by five serotypes (A2, A9, A21, B3 and B4) through different administration routes. Our results indicate that coxsackie $A$ viruses are able to affect both skeletal and heart muscle while the coxsackievirus $B$ subgroup infects a wide range of tissues. In addition to striated muscle these include central nervous system, liver, exocrine pancreas and brown tat. This model makes it possible to analyze molecular factors determining tissue tropism. Recently, we have started construction of recombinant viruses using infectious cDNA clones of coxsackieviruses $A 9$ and $B 3$ for mapping of the pathogenetic determinants in the genomes.
M 105 THE DMMUNESPONSE TO THE HEPATITS A AND B VACCDNE. G.Hess, F.Ambrosch, G.Wioderman, W. Melchior, H.L. Bock, A.Safary, R.Clemens, Boehringer Mannbeim GrobH, Mannheim, Germany, Smithkline Beecham, München, Germany. A study was initiated to acess the immuneresposse to heparitis A and $B$ vacine and a combination of both vaccines. Special attention was drawn on the quantiation of the anti-HAV and the IgM ant-HAV response to the bepatitis A veceine.

Three groups of parients were vaceinated at 0,1 and 6 months. Group 1 received 720 IU of hepatitis A vecioce (HAVRDX), group 2 received 20 ug of $\mathrm{HBSAg}$ 720 IUn of hepatitis A vacoioe (HAVRDX), group 2 received 20 ug of $\mathrm{HB}$ vaccine (ENGERIX) and group 3 received both vaccines at the same site. commercially available anti-HBs, anti-HAV and IgM anti-HAV tests from Bochringer Mannbein Germany. Seroconversion rates (anti-HAV mIU/ml) and GMT are feanred in the Table.

\begin{tabular}{|l|c|c|c|c|c|}
\hline month & 0 & 1 & 2 & 6 & 7 \\
\hline $\begin{array}{l}\text { group 1 } \\
\text { anti-HAV }\end{array}$ & 0 & 226 & 382 & 229 & 2632 \\
\hline $\begin{array}{l}\text { group 2 } \\
\text { anti-HBs }\end{array}$ & 0 & 22 & 188 & 216 & 10999 \\
\hline $\begin{array}{l}\text { group 3 } \\
\text { anti-HAV } \\
\text { anti-HBs }\end{array}$ & $\begin{array}{l}0 \\
0\end{array}$ & $\begin{array}{c}252 \\
27\end{array}$ & $\begin{array}{c}442 \\
237\end{array}$ & $\begin{array}{c}261 \\
351\end{array}$ & $\begin{array}{c}3118 \\
12636\end{array}$ \\
\hline
\end{tabular}

Both the SnithKline Beochan test and the commercial tosts from Boehringer Mannhein gave comparable results.

At month 1, the IgM asti-HAV response to the bepatitis A vaccine was degative or bordetine (in two patients). The combined vaccination against hepatitis $A$ and $B$ did not have impact on the antibody response to the individual vaceioes. In conciusion, the study shows that the anti-HAV response to the hepatitis B vaccine can be quantiatively monitorod and that an IgM anti-HAV response is in general not present one month after hepatitis $A$ vaecinarion. A combined vecination agains bepatitis $A$ and $B$ appears desirable and feasable.
M 107 ISOLATION AND CHARACTERIZATION OF POLIOVIRUSES CONTAINING MUTATIONS IN THE YGDD MOTIF OF THE VIRAL RNA-DEPENDENT RNA POLYMERASE, Sandra A. Jablonski and Casey D. Morrow, Department of Microbiology, University of Alabama at Birmingham, Birmingham, AL 35294.

The poliovirus RNA-dependent RNA polymerase (3Dpol) shares a region of homology with all RNA polymerases, centered around the amino acid motif YGDD, which has been postulated to be involved in the catalytic activity of the enzyme. Using oligonucleotide site-directed mutagenesis, the $\mathrm{Y}$ at this motif of $3 \mathrm{Dpol}$ was substituted with $\mathrm{C}, \mathrm{H}, \mathrm{I}, \mathbf{M}, \mathbf{F}$, or $\mathrm{S}$. The enzymes were expressed in Escherichia coli to test in vitro enzyme activity. The $F$ and $M$ substitutions resulted in enzymes with activity similar to the wildtype enzyme. The $C$ and $S$ substitutions resulted in enzymes with intermediate activities, while the $I$ and $H$ substitutions resulted in inactive enzymes. To assess the effects of the mutants on viral replication, the mutant polymerase genes were subcloned into the infectious cDNA of poliovirus. Transfection of cDNA containing the $F$ mutation in $3 D^{p o l}$ gave rise to virus in all of the transfection trials, while cDNA containing the $M$ mutation resulted in virus in only three of 40 transfections. Transfection of cDNAs containing the other mutations did not result in infectious virus The recovered viruses demonstrated similar kinetics of replication as the wild-type virus. An RNA sequence analysis of the $3 \mathrm{DPol}^{\mathrm{pen}}$ ge of both viruses demonstrated that the $\mathrm{Y}$ to $\mathrm{F}$ or $\mathrm{M}$ mutation was still present. No other differences in the 3Dpol gene between the wild-type and F-containing virus were found. The virus containing the $M$ mutation also contained two other nucleotide changes from the wild-type 3Dpol sequence, one of which resulted in a E-to-D change at amino acid 108 of the polymerase. To confirm that the second-site amino acid change found in the 3Dpol gene of the $M$-substituted virus allowed for replication ability, a mutation corresponding to the E-to-D change was made in the polymerase containing the M substitution. Transfection of a cDNA containing the double-mutant $3 \mathrm{Dpol}$ into cells resulted in virus production in $100 \%$ of the transfection trials. These results identify a second region in the RNA polymerase which is affected by mutations in the YGDD amino acid motif. This region is not essential for in vitro RNA polymerase activity, but is important for the replication of the viral RNA. Further studies of the characterization of the interaction of this region with the YGDD amino acid motif are ongoing, to understand the role of this interaction in 3Dpol enzyme function and replication of the viral RNA. 
M 108 ANALYSIB OF THE INFLUENZA VIRUS ENDONUCLEABE THROUGH THE USE OF RECOMBINANT BYBTEMS

Mark Krystal, Moira Hagen, Thomas D.Y. Chung, James $T$. Matthews and Richard $J$. Colonno

Dept. of virology, Bristol-Myers squibb Pharmaceutical Research Institute, P.O. Box 4000, Princeton, NJ 08543-4000

The first step in influenza virus transcription is the binding of the viral transcription is the binding of the vira viral polymerase subsequently cleaves this RNA and uses the $5^{\prime}$ end as a primer for viral mRNA synthesis, we have used a number of recombinant systems to examine the requirements for cleavage of this host RNA. Initially, a novel synthetic substrate was used with purified virus cores to examine the size and sequence requirements for cleavage by the viral endonuclease. It was shown that a single base past the cleavage site is all that is required for cleavage and that base pairing with the viral 3 ' end can play a role in cleavage site specificity. In addition, conditions were developed whereby recombinant-derived polymerase proteins were able to cleave a synthetic substrate, allowing for new approaches in the study of the viral endonuclease.
M 109 CHARACTERIZATION OF THE VIRAL TRANSCRIPTION TERMINATION SIGNAL AND DETERMINATION OF THE CIS-ACTING SEQUENCES INVOLVED IN TRANSCRIPTIONAL REGULATION OF INFLUENZA VIRUS GENES, Xingqiang Li and Peter Palese, Department of Microbiology, Mount Sinai School of Medicine, One Gustave L. Levy Place, New York, NY 100296574

We have studied the transcription termination signal of influenza virus by mutational analysis of model RNAs using the ribonucleoprotein (RNP) transfection system. The synthetic RNA molecules used in this study contain the coding sequence of chloramphenicol acetyltransferase (CAT) in negative sense flanked by $5^{\prime}$ and $3^{\prime}$ noncoding sequences derived from the genomic segments encoding the nonstructural (NS) and neuraminidase (NA) proteins of WSN virus. Two sets of mutants were prepared. The first set contained either shortened or extended stretches of uridines. The stretch of uridines (U) residues close to the $5^{\prime}$ end of vRNAs had previously been shown to be part of the polyadenylation (transcription termination) signal. In the second set of mutants, the $U$ tract was either shifted away from, or moved closer, to the $5^{\prime}$ end of the VRNA by inserting or deleting nucleotides. The mutant RNA molecules were then examined using the RNP transfection system. We found that the optimal transcription termination signal consists of 5 to 7 uridine residues and the optimal distance between the $5^{\prime}$ end of genomic RNA and the $U$ tract is 16 nucleotides.

We were also interested in determining the cis-acting sequences regulating the differential expression of viral genes. Employing a similar strategy, we found that the recombinant RNA molecule containing the $5^{\prime}$ and $3^{\prime}$ noncoding sequences derived from the hemagglutinin (HA) segment produced 20 times more CAT activity than that of the construct containing the NA ends. This difference closely resembles the normal expression levels of HA and NA genes in infected cells. A series of mutants have been constructed in order to determine the cis-acting sequences responsible for regulating the differential expression of viral genes. The results of this investigation will be presented.

\section{111 MEMBRANE FUSION MEDIATED BY HUMAN}

PARAINFLUENZA TYPE 3: FUNCTION OF THE HEMAGGLUTININ-NEURAMINIDASE. Anne Moscona ${ }^{1}$ and Richard Peluso ${ }^{2}$, Departments of 1Pediatrics \& Cell Biology and 2 Microbiology, Mount Sinai School of Medicine, NY, NY 10029. Human parainfluenza virus type 3 (HPF 3 ), a member of the paramyxovirus group of viruses, is an important agent of respiratory disease in children. In tissue culture, the hallmark cytopathic effect of acute (low-multiplicity) infection with HPF 3 is extensive cell fusion, leading to syncytium formation. While the fusion glycoprotein $(F)$ is critical for membrane fusion, our previous work revealed that for HPF 3 , the hemagglutininneuraminidase $(\mathrm{HN})$ is also essential to the fusion process; an important role for the HPF $3 \mathrm{HN}$ in the fusion process has also been shown in co-expression experiments. We demonstrated that it is, specifically, interaction between $\mathrm{HN}$ and its sialic acidcontaining receptor on cell surfaces that is required for HPF3mediated cell fusion. Syncytium formation can be prevented in a low-multiplicity infection by the addition of neuraminidase to the cells. Under these conditions, the infected cells do not fuse, but the virus spreads throughout the culture, and the cells become persistently infected and remain free of syncytia. Our interpretation of these events is that by removing some cell surface sialic acid receptors, the neuraminidase treatment prevents the interaction of the viral $H N$ glycoprotein with its receptor which is required for cell fusion. Blocking cell fusion during the early phase of the infection allows the establishment of persistent infection. We have recently isolated variant HPF 3 viruses that have greatly increased ability to fuse cells. Cloning and sequencing of the $F$ and $H N$ genes from these variants revealed single amino acid changes in the $\mathrm{HN}$ protein and no atterations in the $F$ protein sequence. We have identified several single amino acid changes in the HN protein that confer increased fusogenicity without altering neuraminidase enzyme activity. Further studies are underway to characterize the alterations in $\mathrm{HN}$ protein function which are responsible for increased fusion. These studies shed light on the mechanism whereby the HPF 3 $\mathrm{HN}$ gene contributes to virus-induced membrane fusion. 
M 112 REPLICATION AND EXPRESSION OF A POLIOVIRUS MINI-REPLICON CONTAINING AN INACTIVE PROTEINASE IN VACCINIA VIRUS INFECTED CELLS, Ruma PalGhosh and Casey D. MorTow, Department of Microbiology, University of Alabama at Birmingham, Birmingham. Alabama 35294

We have constructed a chimeric HIV-2-gag-poliovirus mini-replicon in which regions of the gag gene of HIV-2 has been inserted in the poliovirus genome between nucleotides 1174 and 2470 . Transfection of this chimeric RNA into HeLa cells or poliovirus infected HeLa cells results in the expression of an HIV-2-gag-PI fusion protein which can be imnunoprecipitated using antibodies to HIV-2-gag. Expression of the HIV2-gag-Pl fusion protein was dependent upon replication of the chimeric RNA genome. Interestingly, transfection of the chimeric HIV-2-gagpoliovirus genome into vaccinia virus infected cells resulted in increased replication as evidenced by expression of the HIV-2-gag-Pl fusion protein. To characterize this system, we constructed a mutation in the $2 \mathrm{~A}$ gene to change a cysteine at amino acid 109 to a serine. Expression of the HIV-2gag-Pl fusion protein was not detected when the HIV-2-gag-poliovirus genome containing the $2 \mathrm{~A}$ mutation was transfected into HeLa cells, demonstrating that the mutation is lethal for replication. The replication and expression of the mutant genome was not complemented when transfected into poliovirus-infected cells. However, transfection of this genome into vaccinia virus-infected cells resulted in expression of two proteins with larger molecular mass than the HIV-2-gag-Pl proteins, possibly representing $\mathrm{HIV}-2-g a g-\mathrm{Pl}-2 \mathrm{~A}$ and $\mathrm{HIV}-2-$ gag-Pl-2ABC fusion proteins. Complementation of $2 \mathrm{~A}$ mutation was detected after transfection of the chimeric HIV-2-gag-poliovirus genome containing the $2 \mathrm{~A}$ mutation into poliovirus-vaccinia virus co-infected cells as evidenced by partial processing of the two larger HIV-2-gag-Pl fusion proteins to give the correct size HIV2-gag-Pl fusion protein. The 2A mutation was reconstructed back into the full-length infectious cDNA of poliovirus. Transfection of this cDNA into vaccinia virus infected cells followed by immunoprecipitation with anticapsid antibodies demonstrated the presence of two proteins with molecular mass larger than P1, possibly PI-2A and Pl-2ABC fusion proteins. The results of this study suggest the proteinase activity of $2 \mathrm{~A}$ is not required for RNA replication and demonstrate use of poliovirus mini-replicons as a means to study poliovinus RNA replication.

\section{114 HEPATITIS A VIRUS PROTELNASE 3C CLEAVES} INTERMOLECULARIY IN P1, P2 AND P3, Tina SchultheiB*,Yuri Kusov+ and Verena Gauss-Muiller*, Institute for Medical Molecularbiology, Medical University of Ltibeck, 2400 Libeck, Gennany,+Pres. address: Instinure for Clinical Microbiology and Irnmunology, St.Gallen, Swizzerland

Heparitis A virus (HAV) is a member of the picomavinus family and contains a plas-stranded RNA as genome. The capsid is icosahedral and nonenveloped. The genome was found to have an organization charateristic of the vinus family. Its transiation leads to a polyprotein of approximately $251 \mathrm{kDa}$. In picomaviruses almost all of the proteolytic cleavages within the polyprotein are usually due to the activity of virusencoded proteinases $\mathrm{L}, 2 \mathrm{~A}$ and $3 \mathrm{C}$.

Though belonging to the Picomaviridae HAV is distinguished by some intriguing properties like high thermic stability of the manure virus particle and umusually slow replication in cell colture with no cytopathic effect on most cells. Comparison of amino acid sequences of HAV with other picornaviruses suggests that differences in the polyprotein processing of this virus might account for the protracted course of infection.

Our work is concentrared on the role of the proteinase $3 C$ which was expressed in $E$. coli either as a mature enzyme or as a protein fused to the entire polymerase 3D or to distinct parts of the P3 region. After idenificarion of the recombinant products by coomassie staining and immunoblot intermolecular cieavage acrivity was demonstrated: in vitro translation of synthetic transcripts representing different parts of the viral polyprorein yielded radiolabelled substrates which were incubated with extracts of rransformed bacteria containing recombinant HAV $3 \mathrm{C}$ Identification of cleavage products by immunoprecipitation suggests that HAV $3 C$ can cleave at the P1-P2 junction, within P1 and also within P2 and P3.
M 113 RNA - PROTEIN INTERACTIONS AT THE $3^{\prime}$ INVOLVED IN INITIATION OF POSITIVE STRAND RNA REPLICATION. Holger $\mathrm{H}$. Roehl and Bert L. Semler, Department of Microbiology and Molecular Genetics, College of Medicine, University of California, Irvine, CA 92717

The genome of poliovirus (PV) consists of a single stranded RNA of positive polarity. PV RNA replication proceeds via a negative strand intermediate to produce new positive strand RNAs. This process is catalyzed, in part, by a virally encoded RNA-dependent RNA polymerase termed $3 \mathrm{D}$ polymerase. To identify proteins involved in the formation of replication complexes at the $3^{\prime}$ end of $P V$ negative strand RNA, five constructs have been generated which were used to transcribe various 3 ' end negative strand RNA fragments. The longest RNA, 745 nucleotides, contains sequences complementary to the entire 5 ' noncoding region. The other four transcripts contain N224$\mathrm{N} 2$ (positive strand numbers), N180-N2, N108-N2, and N66-N2 respectively, and each successively shorter RNA has a computerpredicted stem loop deleted. It was determined that at 6 hours after PV infection, maximal amounts of negative strand RNA are present as templates for positive strand synthesis. Cytoplasmic extracts from infected and mock-infected HeLa cells were prepared at this timepoint to produce protein fractions for in vitro complex formation studies. Employing UV-crosslinking assays, a distinct difference in binding of protein complexes from infected and mock-infected extracts to the radiolabeled transcripts was observed. We are presently determining the biological relevance of these RNA-protein complexes to PV RNA replication by investigating the involvement of viral proteins in complex formation.

\section{115 THE PH REGULATION FUNCTION OF THE INFLUENZA A VIRUS MZ PROTEIN, Carol A. Thompson, Finola $H$. Geraghty and Alan J. Hay, National Institute for Medical Research, London, U.x.}

The influenza A virus $M 2$ protein is a $70 \mathrm{kDa}$ tetrameric protein which forms an ion permeable channel. specific inhibition of $M 2$ by amantadine identifies two roles in infection: in virus uncoating and in the regulation of $\mathrm{pH}$ within the transport pathway, which is necessary for the transfer of native HA glycoprotein to the surface of certain virus infected cells. A related activity of the protein in dissipating $\mathrm{pH}$ gradients across the plasma membrane can be assessed directly by measurements of cytoplasmic $\mathrm{pH}$ using the dual wavelength $\mathrm{pH}$ probe SNARF-1. An approximate $0.4 \mathrm{pH}$ unit decrease in the cytoplasmic pH of MDCK cells is observed 3-6 hours p.i., which parallels $M 2$ production. That this $\mathrm{pH}$ change is due to $M 2$ is confirmed by its specific reversal by amantadine and blocking by anti-M2 antiserum. Similar M2-spectfic pH changes have also been observed in M2-expressing MEL cells. The results of studies on the nature of ion changes within the infected cells will be discussed. 
M116 CHARACTERIZATION OF THE SUBGENOMIC MRNA PROMOTER OF THE CORONAVIRUS MHV-A59, Robbert van der Most, Netty Dorrestijn and Willy Spaan, Dept. of Virology, Institute of Medical Microbiology. Faculty of Medicine, Leiden University, postbus $320,2300 \mathrm{AH}$, Leiden, The Netherlands.

Coronaviruses are enveloped viruses containing a single-stranded RNA genome of positive polarity. During infection, the coronavirus mouse hepatitis virus (MHV) synthesizes a nested set of six or seven subgenomic mRNAs (sgRNAs). These sgRNAs contain a common leader that is derived from the $5^{\prime}$ end of the viral genome. Current data indicate that a sequence of 10 to 20 nucleotides ( $n t$ ), located in the intergenic regions, functions as a promoter for sgRNA synthesis. Since the promoter sequence is also present near the -undetermined$3^{\prime}$ end of the leader RNA, a model has been proposed in which basepairing between a $(t)$ sense leader RNA and a promoter on the viral (-)strand is crucial, i.e. the leader transcript serves as a primer for sgRNA synthesis.

To investigate the mechanism by which the leader RNA binds to the promoter and is elongated into the subgenomic mRNA, we have used a cloned synthetic defective interfering (DI) RNA in which the 20 nt mRNA7 promoter, located on a 23-nt double-stranded oligonucleotide was inserted. Following RNA transfection into MHV infected cells, this DI RNA was replicated efficiently and a $0.4 \mathrm{~kb}$ sgRNA was synthesized. The sgRNA consisted of a leader sequence directly fused to the $3^{\prime}$ non-translated region, which was indeed expected if the sgRNA was synthesized from the DI template.

Using this approach we performed an extensive mutational analysis of the promoter. The following observations were made: (i) reduction of the promoter sequence from 20 to 10 nucleotides, creating the natural mRNA3 promoter, does not significantly affect the level of sgRNA, i.e. the extend of basepairing between the leader and the promoter is not the sole determinant for transcription efficiency, (ii) single nucleotide mismatches are tolerated in the $20 \mathrm{nt}$ mRNA7 promoter, but not in the $10 \mathrm{nt}$ mRNA3 promoter. Furthermore, the introduction of multiple mismatches in the mRNA7 promoter allowed us to determine at which nucleotide(s) the leader RNA is elongated after the initial priming event.

M 118 MULTIPLE FUNCTIONS OF PICOANAVIRUS PROTEINASES AS TARGETS FOR THERAPEUTIC INTERVENTION, EckErd Wimmer, Christopher U.T. Hellen, Kevin S. Harris, Thomas Haemmerle, Akhteruzzaman Molla, and Aniko V. Paul, Department of Microbiology. SUNY at Stony Brook, Stony Brook, NY 11794

Picornaviruses, a large family of pathogenic viruses, synthesize only one polypeptide, the polyprotein (PP). Proteolytic processing of the PP to functional viral proteins commences cotranslationally, and is catalyzed by proteolytic activities of the PP itself. All picornaviruses encode a $20 \mathrm{kD}$ $3 C^{p 0}$, but only the entero- and rhinoviruses encode also a $18 \mathrm{kDa} 2 \mathrm{Apro}^{\mathrm{pr}}$ two sulfhydryl proteinases with a proposed serine protease structure. The catalytic triads of the enzymes have been determined, and cleavage specificities, whether intra (cis) or inter (trans) molecularly, has been analyzed, either by expression of polyproteins, or by analyses with purified enzymes. Interestingly, precursor polypeptides in the cascade of proteolysis may have functions in viral replication distinct from the products. This has been shown for $3 C D^{\text {pro }}$ (the precursor to $3 C^{\text {sro }}$ and polymerase $30^{\mathrm{po}} \mathrm{l}$, which is responsible for proteolytic cleavage of the capsid precursor. Moreover, $3 C D^{p 0}$, but not its cleavage products, has the ability to bind to the $5^{\prime}$ end of the viral genome. Insertion of IRES elements into the viral genome allow to dissect the PP genetically; this has led to the surprising observation that $2 A^{\text {pro }}$ is involved also in genome replication. $2 A^{\text {ro }}$ is also responsible, by unknown mechanisms, for shut-off of host cell protein synthesis, the major mechanism of cell killing. The multiple functions of the proteinases offer an expanded target size for chemotherapeutic intervention of picornaviral disease. We will discuss specific inhibitors for 2Avo that may have therapeutic value in the treatment of entero- and rhinoviral disease.

\section{117 THE NUCLEAR ENTRY OF MICROINJECTED INFLUENZA VIRUS RIBONUCLEAR PROTEINS}

Gary Whittaker, Iris Kemler and Ari Helenius Department of Cell Biology, Yale University School of Medicine, New Haven CT 06510

We are studying the uncoating and nuclear transport of incoming influenza virus (WSN) in the host cell. Our previous results $(1,2)$ suggested that an acid-induced $M 1$ dissociation is required for the nuclear entry of viral ribonuclear proteins (vRNPs). To analyze the requirements for the import step in more detail we have used a microinjection approach. Influenza virus RNPs were isolated at $\mathrm{pH} 7.8$ or at $\mathrm{pH} 5.5$ and were essentially free of the virus matrix protein M1. Microinjection of these vRNPs into CHO or MDCK cells resulted in the transport of the core structures into the cell nucleus, as determined by indirect immunofluorescence using antinucleoprotein (NP) antibodies. The core structures that entered the cell nucleus were competent for viral replication, as determined by expression of hemagglutinin (HA) subsequent to injection. As was found previously for infection by influenza virus, import of vRNPs was blocked by co-injection of the monoclonal antibody RL-1 (specific for a component of the nuclear pore) and by incubation of cells at $4{ }^{\circ} \mathrm{C}$. This suggests that the injected RNPs are entering the nucleus by the same mechanisms that take place during virus infection. Nuclear uptake of micro-injected vRNPs was not affected, however, by treatment of cells with the anti-viral drug amantidine, an efficient inhibitor of nuclear uptake in the normal entry pathway. The amantidine-sensitive step in the entry pathway of influenza virus therefore occurs upstream from the nuclear entry step. We concluded that, while nuclear uptake of vRNPs does require dissociation of $\mathrm{M} 1$, it does not require acid induced changes in the vRNPs.

1 - Martin and Helenius (1991). J. Virol. 65 : 232-244

2 - Martin and Helenius (1991). Cell $67: 117-130$ 
Funcrional Analysis of Viral Genomes and Gene Expression: DNA Viruses

$M 200$ INDUCTION BY HERPES SIMPLEX VIRUS OF E2FDEPENDENT DNA BINDING ACTIVITIES, Steven

L. Bachenheimer, Department of Microbiology and Immunology, University of North Carolina School of Medicine, Chapel Hill, NC 27599

Infection of $\mathrm{C}-33 \mathrm{~A}$ celis by herpes simplex virus resulted in the induction of DNA mobility shift activities corresponding to E2F monomer and E2Fcontaining multiprotein complexes. The RB-related protein p107, and a cell cycle regulated kinase consisting of cyclin A and cdk2, were identified as components of the E2F-dependent complex having the slowest relative mobility. These studies were based on the ability of specific antibodies to further retard or disrupt gel shift activities. The role of viral encoded proteins in the induction process was investigated with viral mutants. Extracts prepared from cells infected with a series of viruses expressing mutated forms of ICP4 (vi13), ICP27 (d27-1, n59r)) or ICP8 (n2, nio, d301) were indistinguishable from uninfected cell extracts, suggesting that these viral encoded proteins are necessary for induction of the E2Fdependent activities. Extracts prepared at various times post infection with WT virus demonstrated that the induction of the E2F/p107/cyclinA/cdk2 activity coincided with the appearance of ICP4, ICP27 and ICP8 as determined by Western blot and pulse-labeling experiments. Inspection of the amino acid sequence of ICP8 revealed similarities with conserved domains of E1A, E7 and T Ag which are critical for disruption of $R B-E 2 F$ interactions. Studies are currently underway to determine whether ICP8 has a direct role in the release of E2F from a protein which blocks DNA binding. These results suggest a model in which HSV proteins mediate binding of E2F to DNA and the formation of multiprotein complexes involving $\mathrm{E} 2 \mathrm{~F}$ and a cell-cycle regulated kinase.

M 202 PURIFICATION AND CHARACTERIZATION OF THE HPV-11 E1 AND E2 REPLICATION PROTEINS, Gary L. Bream, Carol-Ann Ohmstede, Jeanne Wilson and William C. Phelps. Div. of Virology, Burroughs Wellcome Co. Research Triangle Pk, NC 27709

The study of Human Papillomavirus replication has been hampered by the lack of a system which reliably supports virus replication. The recent demonstration by Yang et al (Yang, L. et al, Nature 353: 628-632, 1991) of cell-free replication of BPV-1 suggests that a similar system could be used to study HPV replication control. By analogy with BPV, we have focused our attention on the products of the E1 and E2 ORF's which are the only viral proteins required for replication of the virus. We have overexpressed the full-length E1 and E2 proteins of HPV -11 in insect cells. Our analysis indicates that the E2 produced in Sf9 cells is fully active for DNA-binding, and like BPV, the E1 and E2 proteins complex within these cells. We have utilized these two properties to purify the E1-E2 complex using an E2-specific DNA affinity column. Experiments to determine the amino acid sequences required for complex formation are underway. Both proteins localize to a DNA fragment which contains the viral origin of replication. In addition we have detected an ATPase/GTPase activity specific to E1 which is likely part of an energy generating system coupled to a helicase activity which has been predicted for the E1 protein. We have demonstrated that the HPV-11 E1 and E2 proteins possess the same replication associated activities exhibited by the corresponding BPV proteins suggesting that the replication activities of these viruses are tightly conserved.
M 201 TRANSCRIPTION-DEPENDENT RECOMBINATION IN PAPOVAVIRUS DNA, Danielle Bourgaux-Ramoisy, Chantal Nault, Louis Delbecchi and Pierre Bourgaux, Department of Microbiology, The Medical School, Université de Sherbrooke, Sherbrooke, Québec, Canada JiH SN4.

We have observed previously that in polyomavirus(Py)-based replicons, homologous recombination between two short direct repeats ( $\mathrm{S}$ repeats), one on either side of the viral regulatory region (Ori), is strongly stimulated by a sequence included in the Ori and overlapping with the viral early promoter (EP). We have now dissected this region using a cellular system which permits autonomous replication of viral DNA that is transcriptionally defective. Thus, we have observed that deletions of the EP region which include either the TATA box and large tumor antigen (LT)-binding sites B and C, or the TATA box and LT-binding site $C$, are effective in inhibiting recombination between the $S$ repeats. A 7 bp substitution of the sequence inluding the TATA box (bp 120 to 127) was also observed to inhibit recombination. In contrast, a deletion of 45 bp including the TATA box and LT-binding site B had relatively little effect on the ability of the DNA to recombine, an observation consistent with the notion that binding of LT to site B may be repressing early transcription. None of the above-mentioned deletions interfered with viral DNA replication as long as viral early translation products were provided in trans. The possible role of late transcription in recombination was also explored. The Py DNA sequence encompassing both the enhancer and the late promoter (LP) was inserted at the Xho I site of pPvu2035 (Tyndall et al., NAR, 9, $6231-6250,1981)$, in either the direct or the inverted orientation. Both types of resulting Py genomes replicated in the absence of trans-acting viral early proteins, but only those with L.P in the direct orientation recombined. In Py replicons therefore, recombination is regulated by discrete elements which, while being clearly distinct from those regulating replication, are not readily separable from the ones regulating transcription. In conclusion, recombination between repeats flanking the viral Ori appears to depend upon concerted transcription proceeding from both the EP and the LP.

M 203 DETECTION OF IE-, EARLY AND LATE VIRAL ANTIGENS OF HCMV BY IMMUNOHISTOCHEMISTRY IN ACUTE GASTRITIS

Inge Chaloupka *, Christian Sinzger, Bodo Plachter, Stefan Stenglein, Bernd Spriewald and Gerhard Jahn

Institut für Klinische und Molekulare Virologie, Universität ErlangenNürnberg; * Institut für Med. Mikrobiologie, Univers. Leipzig

HCMV gastritis frequently occurs in immunocompromized patients. To analyze viral antigen expression in gastric biopsies from a renal transplant recipient with gastritis, different specific monoclonal antibodies were used in immunohistochemical analyses. Monoclonal antibody (mab) E13, directed against proteins encoded by IE-regions 1 and 2 of HCMV stained morphologically altered as well as unaltered cells. In contrast to that, mabs $\mathrm{CCH} 2$ and XP1, directed against the early antigen p52 (ICP36 ) and the late antigen pp150 (BPP), respectively, only stained morphologically altered cells. In gastric biopsies obtained before tratment with ganciclovir, all three viral antigens were found in smooth muscle, stromal and epithelial cells. Cells positive for IEAg were the predominant infected cell population in these sections. This immunohistochemical pattern was considered to mirror unrestricted acute HCMV infection in different tissue layers of the stomach. After onset of therapy with ganciclovir, viral antigen-positiv peripheral blood polymorphonuclear cells were not detectable anymore. In addition viral antigens appeared to be almost completely cleared from smooth muscle and stromal cells. In these tissue specimens, the IE-, early and late viral antigens were found exclusively in epithelial cells. In contrast to the initial biopsies obtained before therapy, all stained cells showed characteristic alterations (cytomegalic cells). These alterations in viral antigen expression may reflect the effects of antiviral therapy. Immunohistochemical analysis of tissue sections using different antibodies reflecting the antigen expression in the cascade of viral replication may be helpful in diagnostics of acute HCMV infection, monitoring efficacy of antivirals and understanding of pathogenesis on the molcular level of viral gene expression. 
M 204 Simian Virus-40 small-t antigen accelerates DNA replication in vivo Graessmann@, and $M$. Carbone\#. \#Section on Viruses and Cellular Biology, NICHD, Bethesda, MD 20892; @Department of Biochemistry, Freie Universitat Berlin 33, Germany, and Department of Microbiology, Northwestern University, Chicago, IL 60611-3008.

The SV 40 large $T$ antigen is a multifunctional protein essential for the expression and replication of the viral genome. The role of the SV40 small $t$ antigen in these processes is still unclear. We have previously demonstrated that small t protein inhibits SV 40 DNA replication in vitro. In this study we investigated the effect of small t on SV 40 replication in vivo. We microinjected $\mathrm{CV}-1$ cells with wild type SV40 DNA +/vivo. We microinjected CV-1 cells with wild type SV40 DNA +/-
purified small t protein. SV40 DNA replication was accelerated 3-5 fold in cells co-injected with purified small t. Similar results were obtained following microin jection of CV-1 cells with SV40 small t mutant dl 884 DNA + - small t in CV-1 co-injected with dl 884 and small $t$, we observed both an acceleration of the onset of viral replication and a 3-5 fold increase in the rate of dl 884 replication. These results are in mutants are of smaller size when compared to those obtained with wt SV 40
C. Cicala\#, M. L. Avantaggiati\#, A. S. Levine\#, K. Rundell*, A. agreement with the observation that plaques induced by SV 40 small t

M 205 BIOCHEMICAL CHARACTERIZATION OF THE DNA BINDING DOMAIN OF HSV-1 UL9, Daniel S. Fierer and Mark D. Challberg, Laboratory of Viral Diseases, NIAID, National Institutes of Health, Bethesda, MD 20892

The herpes simplex virus type 1 (HSV-1) UL9 protein binds in a sequence specific manner to the origins of replication (ori), and presumably acts to initiate viral DNA replication. To understand the primary events involved in the initiation of HSV DNA replication, we have begun to characterize the UL9-ori interaction using the DNA binding domain of UL9. It has been shown that a truncated derivative of UL 9 comprising the carboxy-terminal 317 amino acids retains origin binding activity. We have overexpressed this DNA binding domain (t-UL9) and the fulllength protein using the baculovirus overexpression system, and purified these proteins. DNase I footprint analyses showed that the site-specific interactions of the two proteins with the wild-type ori were equivalent. Sedimentation and gel filtration analyses showed that both UL9 and t-UL9 are homodimers in solution at high protein concentrations. UL9 remained a homodimer at concentrations as low as $1 \times 10^{-10} \mathrm{M}$, while $\mathrm{t}$-UL9 dissociated to monomer form at concentrations used to assay DNA binding $(<1 x$ $10^{-6} \mathrm{M}$ ). The deleted portion of the molecule (the amino terminal 634 amino acids), therefore, contributes substantially to the free energy of dimerization. This segment also contributes to higher order protein-protein interactions. We have previously shown by using a mutant ori which contains an insertion of 46 AT base pairs ([AT $\left.]_{23}\right)$, that UL9 causes a pattern of periodic DNase I hypersensitivity in the central AT-rich region when the two flanking high affinity binding sites are occupied, suggesting that UL9 holds the DNA between the two sites in a fixed contormation. In contrast, this periodic pattern was not observed with $\mathrm{t}$-UL9. Addition of UL9 antiserum to $\mathrm{t}-\mathrm{UL}$ - pantially restored the hypersensitivity pattern seen with UL9. We suggest that the antibody links the $t$-UL9 molecules bound at the two sites substituting for protein-protein interactions that are mediated by the N-terminal domain of wild-type UL9. Taken together, these data indicate that the amino terminal two-thirds of UL 9 mediates a variety of protein-protein interactions.

M 207 COEXPRESSION OF THE BPV-1 E5 PROTEIN AND THE B-TYPE PDGF RECEPTOR IS REQUIRED FOR GROWTH OF A MURINE MYELOID CELL LINE. David J. Goldstein ${ }^{1}$. Jacalyn Pierce ${ }^{2}$, Ling-Mei Wang ${ }^{2}$, Weiqun $\mathrm{Li}^{2}$, and Richard Schlegel1. ${ }^{1}$ Department of Pathology, Georgetown University Medical School, Washington, D.C., 20007. 2Laboratory of Cellular and Molecular Biology, NCI, NIH, Bethesda, M.D., 20892.

Using PCR methodology, we have demonstrated that a $150 \mathrm{bp}$ amplification product, located at the junction region of HCMV near the 3 'end of the a-sequence, showed strain specificity among cinical isolates in size and restriction enzyme cleavage pattern (J.Clin. Microbiol.1990, 28, 2602-2607). While sequencing these amplified products, some conserved regions such as the $\mathrm{PAC}-1$ and $\mathrm{PAC}-2$ regions, homologous to the same DNA pattern described in HSV were noted. A computer translation of these amplified sequences into putative protein confirmed the presence of conserved peptides which could be involved in the cleavage/packaging of the viral DNA. Utilizing the amplified sequence of Towne strain as a probe, we have identified an RNA transcript in HCMV infected MRC-5. By Northern blot analysis, the size and the amount of the transcript appeared similar in HCMV Towne and AD169 infected cells. It is defined as a poly (A)RNA when RNA is purified through a poly (dT) column. The size of the transcript is $4.3 \mathrm{~kb}$. In a timed experiment (MOI of 3 ), the transcript appeared at day 3 and reached maximum level at day 6 . In AD169 strain, $M$. Chee (Curr. Top. Microbiol. and Immunol.,(1990) 154,126-169) has described the possible presence of a 36,544 dalton protein encoded by this region. It is our intent to enrich this mRNA fraction by hybrid selection and translate it "in vitro" to further characterize this protein.
The 44-amino-acid E5 protein of bovine papillomavirus type 1 (BPV-1) is a highly hydrophobic protein that transforms cells through the activation of growth factor receptors. To investigate the ability of the E5 protein to induce mitogenic signalling through growth factor receptors, we utilized a nontumorigenic, murine myeloid cell line (32D) which is strictly dependent on interleukin 3 (IL-3) for sustained proliferation in culture. This dependence on $\mathrm{IL}-3$ can be functionally substituted by the stimulation of signal transduction pathways mediated by a variety of growth factor receptors following addition of the corresponding ligand. Several receptor cDNAs were used to transfect $32 \mathrm{D}$ cells constitutively expressing the E5 protein to test for IL-3independent growth. Of several receptors tested, only the B-type PDGF receptor was capable of abrogating the dependence on $\mathrm{IL}-3$ for indefinite proliferation in culture. The mitogenic signalling induced by the coexpression of the $B$ PDGF receptor and ES was characterized by stable complex formation between these proteins and the specific stimulation of tyrosine phosphorylation of the receptor only in cells expressing both proteins. These results demonstrate that the BPV-1 E5induced mitogenic activity in $32 \mathrm{D}$ cells functions specifically through the complex formation with the B PDGF receptor and stimulation of its tyrosine phophorylation. 
M 208 ROLLING CIRCLE DNA REPLICATION IN VTTRO WITH PURIFIED HERPES SIMPLEX VIRUS TYPE I REPLICATION PROTEINS, J.Gottlieb and M.D. Challberg, Laboratory of Viral Diseases, National Institutes of Health, Bethesda, MD 20892

Genetic studies have shown that seven herpes simplex virus type I (HSV1) gene products are essential for origin-dependent DNA replication and biochemical functions have been ascribed to the products of these genes: The UL9 gene encodes an origin recognition and binding protein; UL29 (ICP8) encodes a single-stranded DNA binding protein; ULS, ULS and ULS2 encode the three subunits of the helicase-primase complex; UL 30 $(P O D)$ encodes a DNA polymerase; and ULA2 encodes a polymerase accessory protein that acts to stimulate the processivity of the DNA polymerase. To gain further insight into how the individual protein components interact at a replication fork we have reconstituted rolling circle DNA replication in vitro using purified HSV replication proteins.

The preformed replication fork was constructed by annealing the $3^{\prime}$ terminal 30 bases of an 80 base DNA oligonucleotide to a single-stranded pBS circle leaving an unpaired 50 base 5 ' tail. The substrate did not contain an HSV origin of replication and DNA synthesis did not require the presence of the origin recognition protein, UL9. Rolling circle DNA synthesis, however, absolutely required the presence of the other six viral replication proteins. Little or no DNA synthesis occurred with primers that lacked a $5^{\circ}$ unpaired tail while optimal DNA synthesis required an unpaired tail of at least 30 nucleotides. DNA synthesis produced nascent strands that ranged in size from one to ten times unit length $\mathrm{pBS}$. Time course experiments indicated that the rate of synthesis was approximately $300 \mathrm{nt} / \mathrm{min}$. A significant portion of the reaction products could be digested with restriction enzymes that act exclusively on double-stranded DNA. Therefore, lagging strand, as well as leading strand DNA synthesis occurred in this system.
M 209 INDIRECT EVIDENCE FOR THE OCCURRENCE OF AN EBVHIV HYBRID VIRUS: INTEGRATION OF THE HUMAN IMMUNODEFICIENCY VIRUS TYPE 1 INTO THE EPSTEIN-BARR VRRUS. Patricia C. Guenthner, William M. Switzer, Karen A. Gutekunst, Alison C. Mawle, Robert C. Bohannon*, Thomas M. Folks, and Daniel P. Beduarik, Retrovirus Diseases Branch. Division of Viral and Rickettsial Diseases, Centers for Disease Control and Prevention, 1600 Clifion Road, NE, Atlanta Georgia 30333; *ONASCO Biotechnologies, Jnc., P.O. Box 720252, Houston, Texas, 77272-0252.

Our objective in these experiments was to determine whether the human immunodeficiency virus type 1 (HIV-1) can integrate into the Epstein-Barr vinus (EBV) genome. To accomplish this goal, the human B-cell tine AA2, a CD4+cell line containing multiple copies of EBV, was acutely infected with HIV-1 (LAV). EBV episomal DNA was fractionated by pulsed-field gel electrophoresis, isolated, and tested for the presence of EBV and HIV sequences using polymerase chain reaction (PCR) technology. The resulting PCR products were electrophoresed, transfered to nylon membranes, and subsequently hybridized with corresponding EBV and HIV probes. Southern analysis of the PCR reactions generated from the AA2 episomal DNA yielded DNA products of the expected size specific for both EBV and HIV. The pulsed-field purified DNA was analyzed for the presence of contaminating chromosomal DNA containing integrated HIV by performing PCR using actin-specific primers. The PCR reactions employing actin primers produced no observable bands. The possibility of circular, unintegrated HIV contaminating the EBV episomal DNA fraction was tested by mixing the genomic DNAs of the simian cell lines $\mathrm{FeCl}$, which contains EBV episomal DNA, and the human T-cell line A3.01 which was acutely infected with HIV-1. Episomal DNA was isolated by pulsed-field gel electrophoresis; identical PCR and Southern blotting techniques were performed as described. Bands were visualized employing EBV-specific probes, but not for HIV-specific probes on the membranes for the mixed FeCl/HIV-infected A3.01 DNA. The data from the southern analysis of the AA2 DNA PCR amplifications using HIV and EBV primers indicated that both HIV and EBV DNA sequences were present in the episomal fraction of the cellular DNA. The negative results obtained from the amplifications of the same DNA with actin primers, and from those amplifications on the mixed $\mathrm{FeCl}$ /A3,0l(HIV episomal DNA fraction verifies that the amplified HIV sequences were not due to contaminating chromosomal DNA fragments containing integrated HIV which comigrated with the episome, or from unintegrated, circular HIV trapped in the EBV episomal DNA. Direct evidence for the integration of HIV into the EBV genome remains to be elucidared.

\section{210 INHIBITION OF HERPES SIMPLEX VIRUS INFECTION BY ANTISENSE OLIGONUCLEOTIDES, Ronnie Hanecak, Vickie Driver, Bruce MacDonald, Raana Azad, Cliff Ford, and Kevin P} Anderson, ISIS Pharmaceuticals, Carlsbad, CA 92008

Phosphorothioate oligonucleotides complementary to mRNA transcripts encoding essential HSV gene products were examined for antiviral effects in cell culture assays. Antiviral activity was initially determined by 96 -well immunoassay (ELISA) using primary human dermal fibroblast (NHDF) cells under serum-free conditions. Dose-response comparisons of antisense oligonucleotides resulted in the identification of 5 compounds with potent anti-HSV activity. All compounds inhibited several HSV-1 strains including acyclovir resistant isolates, and HSV-2. $90 \%$ inhibition of infectious virus yield was achieved at a concentration of $3 \mu \mathrm{M}$. Structure-antiviral activity relationships were determined by ELISA. Sequence comparisons of active oligonucleotides resulted in the identification of a sequence motif common to all 5 antisense oligonucleotides which was required for maximal antiviral activity. However, sequences flanking the motif also contributed to antiviral activity. Time-of-addition experiments showed that phosphorothioate oligonucleotides at a concentration of $12 \mu \mathrm{M}$ nonspecifically inhibited HSV infection only when added with the virus ( $t=0 \mathrm{hrs}$ ). However, antisense oligonucleotides designed to target essential HSV mRNAs inhibited HSV-1 replication when added as late a 11 hrs. postinfection. Several oligonucleotides showing activity in HSV viral inhibition assays also inhibited human cytomegalovirus (HCMV AD169), influenza virus, and human imunodeficiency virus (HIV) suggesting an alternative mechanism of action. The same oligonucleotides did not inhibit human rhinovirus, poliovirus or adenovirus. Active oligonucleotides showed only minimal cytotoxicity in MTT or neutral red uptake assays at concentrations up to $100 \mu \mathrm{M}$. However, some alterations in cell morphology were evident.

\section{211 THE HUMAN PAPILLOMAVIRUS 16-E2 TRANS-ACTIVATOR REPRESSES TRANSCRIPTION OF THE VIRAL E6-E7 ONCOGENE PROMOTER BY BLOCKING Sp1 BINDING AND COOPERATION WITH BASAL PROMOTER FACTORS, Thomas H. Haugen ${ }^{1}$, Sinikka Parkkinen', Yasushi Yamakawa', Masato Ushikail, Takaoki Ishiji1, Michael J. Lace' ${ }^{1}$, James Anson ${ }^{1}$, Stephen P. Kahanic ${ }^{1,2}$, and Lubomir P. Turek ${ }^{1}$, Departments of Pathology and ${ }^{2}$ Medicine, VAMC and The University of Iowa College of Medicine, lowa City, IA 52242, USA.}

HPV-16 E6 and E7 oncogene promoter, P97, is repressed by papillomaviral E2 gene products interacting with two adjacent proximal E2 sites 5 to a TATAA box. We found that P97 response to cellular enhancer factors required the cooperation between TFIID, Sp1 and possibly additional, as yet undefined factor(s) binding to precisely spaced motifs. The HPV-16 E2 trans-activator increased P97 mRNA levels at low concentrations, but repressed P97 transcription at higher levels, suggesting a possible autoregulatory mechanism for HPV-16 early gene expression. E2 binding did not displace human TFIID (TBP) from the TATAA box in vitro, and spacer insertions between the TATAA and E2 sites did not abolish E2 repression in vivo. In contrast, the HPV-16 E2 protein was found to block Sp1 binding to a motif partially overlapping an E2 site in DNase I footprinting. The insertion of a spacer sequence duplicating this site overlap allowed E2 and Sp1 to bind simultaneously in vitro and relieved $\mathrm{E} 2$ repression in vivo. Like a classical repressor, the E2 trans-activator thus inhibits HPV-16 P97 response to cellular activators by blocking $\mathrm{Sp} 1$ binding and disrupting the cooperation between enhancer proteins and basal promoter factors. These profound effects of the E2 gene product on $P 97$ activity may explain the apparent selection against intact E2 in integrated HPV fragments in cervical carcinomas expressing the viral E6 and E7 oncoproteins. 

M 212 CHARACTERIZATION OF A CELI LINE RESISTANT
TO INEECTION BY THE KOS STRAIN OF HERPES
SIMPLEX VIRUS TYPE 1, Thomas C. Holland,
Department of Immunology and Microbiology, Wayne
State University School of Medicine, Detroit, MI 48201

We have identified a rat kidney cell line, NRK$52 \mathrm{E}$, that is relatively resistant to infection by HSV-I [KOS]. At low MOIs, plaques either did not develop or were extremely small and reduced in guantity At high MOIs, cytopathic effect was delayed and virus yields were reduced about 10 delayed and virus yields were reduced about 10
fold. Experiments to identify the stage in viral replication that is blocked in NRK-52E cells were done. Adsorption of HSV-1 [KOS] was not significantly different from adsorption to permissive Vero cells. penetration, defined by resistance to citrate washing, was studied using an infectious center assay. Penetration into NRK-52E cells occurred at about $1 \%$ of the rate of penetration of Vero celis. HSV-1 [KOS] was also unable to induce host cell shutoff in NRK-52E cells. Since shutoff is mediated by release of a virion component, the virion host shutoff (vhs) protein, into the cytoplasm after penetration and does not require viral gene expression, failure to induce shutoff also suggests a penetration defect. Entry of HSV1 occurs by initial adsorption of the virion to cell surface heparan sulfate proteoglycans, followed by direct fusion of the virion envelope with the plasma membrane. The fusion process requires at least three viral glycoproteins: gB, gD, and gH. It has been suggested that at least one of these glycoproteins, possibly gD, binds to a second cellular receptor. The NRK-52E cell line appears to be defective in some post-adsorption interaction of the virion glycoproteins with the plasma membrane. Additional studies to identify the step blocked in entry of the virus into NRK$52 \mathrm{E}$ cells are in progress.

M 214 HCMV INFECTED PLACENTAL TISSSUE - IDENTIFICATION OF CELL TYPES BY IMMUNOHISTOCHEMICAL DOUBLE STAINING

Gerhard Jahn, Christian Sinzger, Inge Chaloupka, Dietmar Wolff, Susanne Schmolke and Bodo Plachter

Institut für Klinische und Molekulare Virologie, Loschgestraße 7, 8520 Erlangen, Germany

The human cytomegalovirus (HCMV) is the most common cause of congenital and perinatal viral infection. This vertical infection occures in about $1 \%$ of all live births. Intrauterin transmission during primary infection leading to severe sequelae may occur without detectable active or recent viral infection in the mother. The role of the placenta as a site of HCMV acute infection or latency during pregnancy is a very poor defined area in congenital infection.

To better understand the mechanism of HCMV transplacental infection, we studied placental specimens from clinical cases of congenital HCMV infection. The formalin fixed paraffin embedded tissues were investigated to identify the cell types infected by HCMV. Immunohistochemical double-staining analyses were performed using antibodies to HCMV IEAg and to specific cellular marker proteins. In addition, early and late viral antigens were stained with specific antibodies directed against molecular defined epitopes of distinct viral proteins. Fibroblasts could be demonstrated to be the predominantly infected cell type in each placental tissue. Endothelial cells and macrophages were also found to be infected in all cases investigated, whereas evidence of trophoblast infection was only obtained in one case. We conclude, that release of infectious virus by fibroblasts, macrophages and endothelial cells may play an important role in transplacental transmission of HCMV. These findings further suggest, that placental cell damage might be involved in pathogenesis of intrauterine HCMV disease. HCMV infection of human placental tissue seems to be quite different from the animal model of the guinea pig, where the placental cells were found persistently infected by GCMV.
M 213 EXPRESSION OF THE HUMAN HERPESVIRUS 6 HOMOLOG OF THE ADENO-ASSOCIATED VIRUS TYPE 2 REP GENE AND BIOCHEMICAL CHARACTERIZATION OF ITS PRODUCT. Naoki Inoue ${ }^{1}$, Timothy R. Dambaugh ${ }^{2}$, Demetrio Sanchez-Martinez ${ }^{1}$, Geraldina Dominguez ${ }^{1}$, and Philip E. Pellett ${ }^{1}$, ${ }^{1}$ Centers for Disease Control, Atlanta, GA 30333, 2DuPont/Merck Pharmaceuticals, Wilmington, DE 19880.

Human herpesvirus 6 (HHV-6) is the causative agent of exanthem subitum. The virus infects $\mathrm{T}$ lymphocytes, and can establish latency and be reactivated. HHV-6 isolates form two groups, variant A (strains U1102- or GS-like) and variant B (strain Z29-like), based on biological and physical differences. Thomson et al. (Nature 351:78-80,1991) showed that HHV-6A strain U1102 encodes a gene homologous to the rep gene (rep AAV-2 $_{2}$ ) of adeno-associated virus type 2 (AAV-2). Products of $r e p_{\mathrm{AAV}-2}$ play essential roles in DNA replication and have pleiotropic effects on viral gene expression and cellular proliferation. Rep proteins bind to AAV-2 replication origins, and have site-specific endonuclease and ATP-dependent helicase activities. We have begun studies of the role of the HHV -6 Rep product in HHV-6 replication.

We identified a rep homolog $\left(r e p_{\mathrm{H} 6 \mathrm{~B}}\right)$ encoded by a HHV-6B strain (Z29). The identity of both the rep genes and the Rep proteins between HHV-6A and HHV-6B was over $96 \%$. To analyze the functions of the HHV-6 Rep protein $\left(\operatorname{Rep}_{\mathrm{H} 6 \mathrm{~B}}\right)$, we expressed $R e p_{\mathrm{H} 6 \mathrm{~B}}$ in a reticulocyte lysate by in vitro translation and in insect cells by infection with a recombinant baculovirus. We also prepared antisera against $\operatorname{Rep}_{\mathrm{H} 6 \mathrm{~B}}$ by immunizing rabbits with oligopeptides. The apparent molecular weight of the expressed protein was approximately $60 \mathrm{kDa}$, with most of the protein being present in nuclear fractions. Studies of the biochemical properties of $R_{e} p_{\mathrm{H} 6 \mathrm{~B}}$, and of its expression during HHV- 6 infection are under way.

M 215 CHARACTERIZATION OF THE CELL TYPE-SPECIFIC NATURE OF THE HSV - 1 LAT REGULATORY SEQUENCE; Joseph J. Kenny, Renee P. Hinkel, Fred C. Krebs, Heather T. Hartle, College of Medicine, Hershey, PA, 17033

The promoter and surrounding regulatory sequences of the HSV-1 latency-associated transcript (LAT) have recently been shown to be regulated in a cell type-specific manner. We are in the process of constructing a series of PCR deletion mutants of the LAT regulatory sequence (LRS) from +1 to -609 to determine specific sequences within this region involved in cell type-specific regulation of the LAT promoter. The series of deletion mutation CAT constructs have been transiently transfected into a variety of both neuronal and nonneuronal cells. The first increase in activity detected in any cell type examined was observed when LAT regulatory sequences from -33 to -74 were added to the basal promoter construct pLRS1-33, which contains only the TATA element. This result most likely reflects the addition of the Cyclic-AMP Response Element (CRE) and the LAT Promoter Binding Factor(s) (LPBF) sequences to the basal promoter construct. As additional sequences are added upstream from the LPBF site, a 3- to 4-fold neuron-specific or C1300-specific increase in CAT activity is routinely observed. In C1300 cells, a small, but reproducible decrease in CAT activity was observed when sequences from -138 to -178 were added. However, when LAT regulatory sequences were added upstream of -178 , an additional neuronspecific increase in CAT activity was obtained which corresponds to a specific increase in CAT activity was obtained which corresponds to a
40 - to 50 -fold increase when compared to the basal pLRS $1-33$ construct. We have also obtained data which suggests that there may be sequences upstream of -300 that may increase expression levels to greater than 60 fold above those obtained with pLRS1-33. We have utilized a series of double-stranded oligonucleotides as radiolabeled probes to examine the interaction of LAT regulatory sequence DNA with nuclear proteins or protein complexes by gel mobility shift DNA-binding analyses. Specific DNA-protein complexes were detected when nuclear extracts were reacted with four oligonucleotides representing sequences from -178 to -278 . However, we have been unable to detect appreciable complex formation with oligonucleotides representing sequences from -118 to -198 . A minor, but reproducible neuron-specific DNA-protein complex was detected when oligonucleotide $\mathrm{K} 1314(-238$ to -278) was utilized as the target sequence. 
M 216 FINE-MAPPING OF THE HEPATITIS B VIRUS S PROMOTER, C.C. Lu and T.S.B. Yen, Anatomic Pathology 113B, 4150 Clement Street, VAMC, University of California, San Francisco CA 94121

The outer envelope of the hepatitis B virus particle is composed of 3 forms of the viral surface antigens ( $\mathrm{HBsAg}$ ) large, middle, and small (major) forms. All 3 forms are primary translation products arising from a single ORF but utilizing different in-frame start codons. The expression of the middle and small HBsAg is directed by the S promoter which does not have a canonical TATA sequence, and which gives rise to multiple transcripts straddling the initiating ATG codon for the middle HBsAg. In a previous study, we have shown that this promoter contains a CCAAT motif and two initiation regions. We have gone on to characterize the $S$ promoter in more detail, by quantitating RNA and protein expression from linker scanning mutants spanning the entire $130 \mathrm{bp}$ of this promoter. The results confirm the importance of the CCAAT motif and of the initiation regions.

Surprisingly, mutation of sequences between the 2 initiation regions almost completely abrogated all the transcripts. A computer-assisted search revealed homology of this region to cis-elements in the apoCIII and $\alpha$-antitrypsin promoters. Efforts are now underway to characterize the trans-acting factors that bind to these positive elements in the $S$ promoter.
M 217 A HERPES SIMPLEX VIRUS (HSV) SEOUENCE WHICH BINDS A CELLULAR PROTEIN AS EITHER A SINGLESTRANDED OR DOUBLE-STRANDED DNA OR RNA, L. McCormick, R. J. Roller, and B. Roizman, Univ. of Chicago, Chicago IL 60637 We report the following: (1) A cellular protein designated as a nucleic acid protective protein (NPP) binds to a HSV-1 sequence as either single stranded (SS) or double stranded (DS) DNA or RNA and protects single stranded RNA from nucleolytic degradation. The sequence is located at the 5 ' end of Oris RNA - a heterogeneous non coding RNA which traverses an origin of viral DNA synthesis. Approximately half of the Oris RNA (major species) initiates immediately downstream from the sequence bound by NPP. (2) NPP binds to the sequence [N(GTGGGTGGG $\left.)_{2}(\mathrm{~N} \leq 10)\right]$ with the $9 \mathrm{~b}$ repeat positioned at nucleotides -18 to -1 relative to the major Oris RNA. To bind, NPP requires at least 3 guanines between thymines and tolerates insertion of additional thymines but not the insertion of adenines or the substitution of some of the guanines with cytosines in one repeat. Replacement of the ten 3' nucleotides has no effect on binding activity whereas deletion of these sequences abolished it. Among related sequences with no demonstrable binding activity were some telomeric sequences which interact with known cognate proteins. (3) The proteins involved in recognition and binding of the single stranded RNA and DNA appear to be identical. (4) The electrophoretic mobility of the HSV-1 SS DNA sequence in native gels suggests that it forms inter- or intra-molecular seconday strcutures, but the conditions under which they were formed were different from those of optimal NPP binding. (5) Radioactive label in the cognate RNA sequence was transferred by crosslinking to a 100,000 apparent molecular weight protein under conditions which enables binding of NPP to the RNA sequence and (6) A computer search of the 18 base sequence GTGGGTGGGGTGGGTGGG or of mutated sequences revealed that the only NPP cognate sites are uniquely located at the Ori ${ }_{5}$ RNA locus and that other sites do not exist in the viral genome.

Roller, R.J, McCormick A.L and Roizman, B. Cellular proteins specifically bind single- and double-stranded DNA and RNA from the initiation site of a transcript which crosses the origin of DNA replication of herpes simplex virus 1. Proc. Nat. Acad. Sci. (USA) 86:6518-6522, 1989

McCormick, L., Roller, R. J., and Roizman, B. Characterization of a herpes simplex virus sequence which binds a cellular protein as either a single stranded or double stranded DNA or RNA. J. Virol. 66:3435-3447, 1992.

M 219 p53-mediated transcriptional activation is inhibited by SV40 large Tantigen and by HPV-16 E6 oncoprotein, Judy A. Mietz, Tamar Unger, Jon M. Huibregtse and Peter M. Howley, Laboratory of Tumor Virus Biology, National Cancer Institute, Bethesda, MD 20892

The p53 protein is thought to be an important determinant in the control of cell growth. Wild-type p53 has been shown to bind DNA in a sequencespecific manner and the results from a number of recent studies indicate that $\mathrm{p} 53$ functions as a transcriptional activator. It has been presumed that the tumor suppressive function of p53 is abrogated as a consequence of its interaction with the transforming proteins of several DNA tumor viruses. In the present study the effects of SV40 large T-antigen (T-ag) and human papillomavirus (HPV) type $16 \mathrm{E} 6$ proteins on the transcriptional transactivation function of wild-type $p 53$ were examined in human cells lacking endogenous $p 53$ expression. Plasmids expressing human p 53 were cotransfected with various wild-type or mutant T-ag or HPV E6 expression plasmids and assayed for transactivation function using a p53-responsive reporter gene containing multiple copies of the consensus p 53 binding motif, TGCCT. Both T-ag and HPV-16 E6 were able to inhibit transactivation of the test gene by wild-type p53. Several T-ag mutants, defective for $p 53$ binding were unable to inhibit transactivation by $p 53$. Similarly HPV E6 proteins that were either mutant or derived from nononcogenic HPV types and unable to bind $p 53$ had no effect on transactivation. These results demonstrate that viral oncoproteins such as SV40 T-ag and and HPV-16 E6 can inhibit p53-mediated transcriptional activation factor and this ability correlates with the ability of the viral proteins to alter cell growth in transformation assays. 
M 220 THE STATE OF THE MUTATIONAL ALTERATIONS OF THE RETINOBLASTOMA SUSCEPTIBILITY GENE IN HUMAN PAPILLOMAVIRUS.FREE SMALL CELL CARCINOMAS OF THE UTERINE CERVIX, Chia C. Pao, Shu-Min Kao, Jui Hsiung Chen, Gu-Ching Tang, Chieh-Yu Lin, Ding-Shyn Yao, Department of Biochemistry, Chang Gung Medical College and Memorial Hospital, Taipei, Taiwan, Republic of China.

DNA sequences of certain types of HPV were frequently found in anogenital tissues and were thought to be associated with the development of cancers in these tissues. However, the mechanism(s) through which these HPVs induce malignancy were unclear. Recent reports have suggested that HPV E6 and E7 oncoproteins are capable to complex with the products of tumor suppressor genes, p53 and retinoblastoma susceptibility (Rb), respectively. It has been suggested, both in cervical cancer cell lines and in primary cervical cancers, that loss of tumor suppressor gene function is important in the pathogenesis of cervical cancer and that in the absence of an HPVencoded gene product that mediates loss of tumor suppressor function, somatic mutation of the genes is required. We have analyzed the $\mathrm{Rb}$ gene of 12 small cell carcinomas of the uterine cervix that are free of human papillomavirus. Conserved regions of exons 13 and 20 of $\mathrm{Rb}$ gene were amplified and were followed with direct DNA sequencing. We did not detect any mutational alteration in any one of these specimens. These results seem to suggest that although mutational alterations in exons 13 and 20 may be a frequent event in many types of cancer, inactivation of these regions of $\mathrm{Rb}$ gene in small cell carcinomas of the uterine cervix, even if they were free of HPV, is probably not needed for tumor development.

\author{
M 221 KERATINOCYTES IMMORTALIZED BY HPV \\ DNA EXHIBIT ALTERATIONS DEPENDENT \\ UPON HOST GENETIC BACKGROUND AND \\ TRANSFECTED VIRAL GENES. \\ Xu Fang Pei*, Nai Geng Qin**, Jeanne M. Meck ${ }^{* *}$ \\ and Richard Schlegel* \\ * Department of Pathology, ** Department of Obstetric and \\ Gynecology, Georgetown University Medical School, 3900 Reservoir \\ Road NW, Washington, DC. 20007, USA
}

Keratinocytes immortalized by the human papillomaviruses vary in cell morphology, growth properties, resistance to inducers of terminal differentiation, and karyotype. To determine the contribution of the host cell genetic background (as well as the viral DNA) to these cellular alterations, we have generated six human keratinocyte cell lines from two different newbom foreskins ( $A$ and $B$ ) using either the full-length HPV-18 genome or the isolated HPV 18 E6/E7 genes. Cell lines established with full-length HPV-18 DNA were morphologically different from those established by the E6/E7 genes, regardless of foreskin origin. In addition, cell lines established by fuil-length HPV18 DNA also displayed a greater clonal growth potential. All cell lines showed unique DNA integration patterns. The cell lines generated by the E6/E7 plasmid exhibited identical patterns of viral RNA expression whereas those established by full-length HPV-18 DNA showed variable RNA species. Interestingly, cell lines established from foreskin A revealed similar chromosomal alterations, regardless of the viral DNA employed for immortalization, and these karyotypic changes differed from those observed in cell lines established from foreskin B (which exhibited their own characteristic aneuploid profile). Thus, the chromosomal alterations in keratinocyte cell lines induced by HPV are, in part, determined by the genetic background of the donor.

M 223 HERPES SIMPLEX VIRUS (HSV) ENCODES A MULTIFUNCTIONAL RNA-BINDING REGULATORY PROTEIN, R. J. Roller, L. Monk and B. Roizman, University of Chicago, Il 60637 The HSV $\mathrm{U}_{\mathbf{S}} 11$ gene encodes a multifunctional site- and conformationspecific RNA binding regulatory protein with the following characteristics. (1) The $U_{s} 11$ protein is an abundant product of a late gene. $U_{S} 11$ protein is a virion component, present at 600-1000 copies per virion, and is introduced into the host cell immediately upon infection. (2) $U_{s} 11$ specifically binds a cytoplasmic, non-polyadenylated and truncated form of the $U_{L} 34$ mRNA ( $\left.\Delta 34\right)$. The authentic $U_{L} 34$ mRNA encodes an essential, late-expressed viral protein. $U_{\mathbf{s}} 11$ negatively regulates the steady state level of $\Delta 34$ such that in $U_{\mathrm{S}} 11^{-}$virus infected cells, the level of $\Delta 34$ RNA is increased about eight-fold. The DNA sequence in the vicinity of the 3 ' end of $\triangle 34$ RNA is similar to proposed sites of premature termination of transcription in other eukaryotic systems such as the c-myc gene, adenovirus MLP transcription, SV40 late transcription and transcription from the P4 promoter of minute virus of mice. (3) Like the tat and rev proteins of HIV, the $U_{S} 11$ protein localizes in the nucleolus. The $U_{S} 11$ protein binds to $28 S$ rRNA and associates specifically with 6OS ribosomal subunits and fullyformed ribosomes both late in infection and immediately after infection of cells, which may account for its nucleolar accumulation. (4) A stably transfected BHK cell clone which expresses high levels of $U_{s} 11$ protein is extremely resistant to HSV infection, and this resistance is manifested at, or prior to the immediate early phase of infection. We have selected a variant of HSV-1 which can grow in these cells and mapped the mutation which enables growth to the gene for the essential virion surface glycoprotein $\mathrm{gD}$. This strongly suggests that the block to infection is at the point of viral entry, and that some cell surface component with which $g D$ interacts is altered or absent from the surface of the $U_{s} 11$-expressing cells.

Roller, RJ. and Roizman, B. 1990. The herpes simplex virus $U_{s} 11$ open reading frame encodes a sequence-specific RNA-binding protein. $J$. Virol. 64:3463-3470.

Roller, R.J. and Roizman, B. 1991. Herpes simplex virus I RNA binding protein $U_{s} 11$ negatively regulates the accumulation of a truncated viral RNA. J. Virol 65:5873-5879.

Roller, R.J. and Roizman, B. 1992. The herpes simplex virus 1 RNA binding protein $U_{s} 11$ is a virion component and associates with ribosomal 60S subunits. J. Virol. 66:3624-3632. 
M 224 HERPES SIMPLEX VIRUS I GLYCOPROTEINS E AND I ARE REQUIRED FOR ENTRY THROUGH APICAL

MEMBRANES AND FOR CELL TO CELL SPREAD IN POLARIZED EPITHELIAL CELLS. Amy E. Sears" and Bradford 5. MCGwire, Marjorie B. Kovler Viral oncology Laboratories, University of Chicago, Chicago, II 60637

of the 11 surface glycoproteins encoded by $H S V-1$, at least 6 ( $g C, g E, g G, g I, g J$, and $g M)$ are dispensable for growth of the virus in most cells in culture. The cells infected by HSV - during the course of a natural infection in vivo epithelial cells and neurons, are both highly polarized cell types. Previous work has shown that $\mathrm{gC}$ is required for attachment to a receptor found on the apical surfaces of polarized MDCK cells, and another, gCindependent receptor, is present on the basal membranes. In these studies, gE and gI have been shown to be essential for a post-attachment stage of entry of HSV-1 through the apical surfaces of polarized epithelial (MDCK) cells. Recombinant viruses with deletions in $\mathrm{gE}$ or $\mathrm{gI}$ were able to attach to apical membranes but infection, as measurea by gene expression or by electron were able to infect polarized MDCk cells through were able to infect polarized MDCk cells through
the basal membranes. After infection of basal membranes, single infected cells containing nucleocapsids could be detected in the monolayers as assayed by immunoperoxidase staining for viral proteins or by electron microscopy, but progeny virus did not spread into the adjacent cells. Both the $\mathrm{gE}^{-}$and $\mathrm{gI}^{-}$recombinants were able to infect the peripheral endings of sensory neurons of mice and establish latent infections.

These data indicate that the functions of a number of the dispensable glycoproteins of HSV-1 are required to allow the virus to infect and disseminate between polarized epithelial cells. "Current address: Emory University school of Medicine, Department of Microbiology and Immunology, At lanta, GA 30322.

M226 IDENTIFICATION OF FACTORS SPECIFIC FOR TRANSCRIPTION OF VACCINIA VIRUS LATE GENES, Cynthia F. Wright and Asimina M. Colucci, Department of Cellular Pathology, Armed forces Institute of Pathology, washington, D.C. 20306

Extracts made from vaccinia virus-infected HeLa cells are capable of transcribing vaccinia virus late gene templates. This system can be fractionated by chromatography on

phosphocellulose into three components, eluting at different salt concentrations $(0.1,0.3$, and 1.0 M NaCl), which are all necessary for maximal late transcription. Previous work identified one of the components of the phosphocellulose $0.1 \mathrm{M}$ fraction as a $30 \mathrm{kDa}$ protein which is encoded by the vaccinia virus intermediate gene, G8R. The phosphocellulose $0.3 \mathrm{M}$ fraction has now been further purified by chromatography and found to consist of at least two components, both of which are essential for transcription of viral late genes. One component co-purifies with RNA polymerase activity and can be complemented for by extracts made from purified vaccinia virions. The other component has been purified to near homogeneity and appears to be a single polypeptide of approximately $50 \mathrm{kDa}$. This component cannot be complemented for with virion extracts, but is present in extracts from vaccinia virus-infected cells which have been treated with cytosine arabinoside or hydroxyurea to block DNA replication. This result suggests that this protein may be the product of a viral early gene.
M 225 MAPPING THE DOMAINS OF THE BOVINE PAPILLOMAVIRUS-1 E2 PROTEIN WHICH ARE REQUIRED FOR INTERACTION WITH THE E1 PROTEIN, Patricia L. Winokur, Trina R. Sarafi and Alison A. McBride, Laboratory of Tumor Virus Biology, National Cancer Institute, Bethesda, MD 20892

Replication of bovine papillomavirus-1 DNA requires two viral gene products, the E1 protein and the $48 \mathrm{kD}$ full-length E2 protein. The full-length E2 protein forms a complex with the E1 protein and stimulates binding of E1 to the origin of replication. The E2 proteins of various papillomaviruses share two relatively conserved domains, a sequence specific DNA-binding and dimerization domain which is encoded in the Cterminal 85 amino acids and a transactivation region encoded by the $\mathrm{N}$-terminal 200 amino acids. These two domains are separated by a non-conserved internal hinge region. To determine which domains of the E2 protein are required for binding to $\mathrm{E} 1$ and for enhancement of E1 DNA binding, a series of mutations were constructed within the E2 open reading frame which delete various regions of the conserved DNA binding and transactivation domains as well as the internal hinge region. An intact $\mathrm{N}$-terminal domain of the $\mathrm{E} 2$ protein is sufficient for interaction with the $\mathrm{E} 1$ protein. However, an intact C-terminal DNA binding/dimerization domain is important for enhancement of the binding of E1 to the origin of replication. 
Retrolinuses: Nucleic Acid and Packaging.

Viral Structure: Slow Virus Infections

M 300 NUCLEOLAR TARGETING SIGNAL OF HTLV-1 REX PROTEIN SPECIFICALLY BINDS TO

NUCLEOLAR SHUTTLE PROTEIN B-23, Y. Adachi ${ }^{1}$, T.D.

Copeland $^{1}$, M. Hatanaka ${ }^{2}$, and S. Oroszlan ${ }^{1},{ }^{1}$ Laboratory of Molecular Virology \& Carcinogenesis, ABL-BRP, NCI-

FCRDC, Frederick, MD 21702; ${ }^{2}$ Institute for Virus Research, Kyoto University, Sakyo-ku, Kyoto 606, Japan

Rex protein, the posttranscriptional regulator of human Tcell leukemia virus type 1 , is known to be localized predominantly in the cell nucleolus. Rex facilitates the cytoplasmic accumulation of unspliced and singly spliced viral $m$ RNAs. The N-terminal 19 amino acids of Rex was identified as the nucleolar targeting signal (NOS), and has been shown to be important for Rex function. To study the molecular interaction between NOS region of Rex and its binding host protein(s) in the nucleolus, we chemically synthesized NOS and its mutant peptides. Remarkably, the NOS peptide was rapidly taken up by cells, and localized in the nucleolus. Using affinity chromatography with this functional NOS peptide, we identified nucleolar protein B-23 as the major binding protein to NOS. Two highly acidic regions of B-23 (amino acids 117-135 and 159-188) were identified as acceptor regions for NOS. B-23 is thought to function as a shuttle protein for the nucleolar transport of ribosomal components. Our results suggest that B-23 may serve as a shuttle for the import of Rex from the cytoplasm into the nucleolus coupled to the export of viral mRNAs containing Rex-responsive element. (Research sponsored in part by National Cancer Institute, DHHS, under contract N01-CO-74101 with ABL).
M 301 MOLECLLAR ANALYSIS OF POLIOVIRUS ASSEMBLY USING RECOMBINANT VACCINLA VIRUSES TO COMPLEMENT A POLIOVIRUS GENOME WITH A CAPSID GENE DELETION, David C. Ansardi, Donna C. Porter, and Casey D. Morrow, Department of Microbiology, University of Alabama at Bimingham, Birmingham, AL, 35294. Poliovirus capsid proteins are initially synthesized as a polyprotein precursor, Pl, which is myristylated at its amino teminus and is subsequently processed by viral proteases to yield mature virion proteins. We have developed a new system for studying poliovirus assembly which uses a recombinant vaccinia virus to provide capsid proteins in trans to a previously described defective poliovirus genome which coniairs a capsid gene deletion and does not express functional capsid proteins. The recombinant vaccinia vinus (VVP1) expresses the $\mathrm{P} 1$ capsid precursor protein. Transfection of in vitrotranscribed defective genome RNA into cells infected with VVP1 resulted in production of polioviruses which had encapsidated defective genome RNA. Formation of defective poliovirus particles was demonstrated by showing that cells infected with an extract from VVP 1-infected/ defective genome-transfected celis expressed poliovirus protein $3 C D$ and synthesized poliovirus-specific RNA which contained the capsid gene deletion. Furthermore, infection of cells with a defective poliovirus preparation was prevented by prior incubation with antisenm to poliovirus. Since formation of defective poliovirus was dependent on VVPI providing capsid proteins in trans, we were able to use a recombinant vaccinia virus which expresses a mutant unm yristylated $\mathrm{Pl}$ precursor (VVPImyr-) to characterize the imporance of myristylation of P1 for virus assembly. By coinfecting cells with VVP1 myr- and defective poliovirus, we found that myristylation of $\mathrm{PI}$ was required for assembly of mature virus. However, low levels of subviral capsid particles and immature particles containing defective genome RNA were detected. The RNA-containing particles generated in VVP1myr-defective poliovinus coinfected celis did not undergo froteolytic cleavage of capsid protein VPO to VP2 and VP4, which normally occurs upon RNA encapsidation. Assembly of unmyristylated viral particles was in contrast to our earlier studies on assembly of unmyristylated capsid proteins in cells coinfected with VVPImyr-and a second recombinant vaccinia virus which expresses poliovirus protease $3 \mathrm{CD}$. In those studies, $3 \mathrm{CD}$ processed unmyristylated P1 to VPO, VP3, and VP1, but assembly of subviral particles was not detected. These results demonstrate that viral RNA facilitates the necessary protein-protein interactions required for assembly of poliovirus subviral particles.
M 302 SEQUENCE COMPARISON OF MINK AND FERRET PrP GENES, Jason C. Bartz, Debbie I. McKenzie, R.F. Marsh, and Judd M. Aiken, Department of Animal Health and Biomedical Sciences, University of Wisconsin, Madison Wisconsin 53706. Spongiform encephalopathies are an unusual class of diseases that affect sheep, cattle, mink, ferrets, mule deer, elk, and humans. Accumulation of a isoform of a cellular protein (PrPres) accompanied by an extended incubation period of months to years is characteristic of these diseases 1 . Previous studies have shown a strong influence of the PrP gene on the species barrier. ${ }^{2}$

The basis of this investigation has been the characterization of the PrP gene in mink and ferrets. Transmission studies have previously show that ferret adapted transmissible mink encephalopathy (TME) cannot be reintroduced into mink This irreversible species barrier is unprecedented in spongiform encephalopathies. Investigations into the nature of the $\operatorname{Pr} P$ gene in mink and ferret should provide insight into the role of $\operatorname{PrP}$ in the species barrier effect. We have amplified the PrP coding region from both mink and ferret DNA using the polymerase chain reaction. Sequence analysis shows seven silent base changes and only two codon changes, a Phe $\rightarrow$ Lys at codon 179 and Arg $\rightarrow$ Gln at codon 224 between mink and ferret. These codon changes may indicate the precise region of $\operatorname{Pr} P$ that is responsible for the species barrier effect. Further studies are underway to characterize expression of $\operatorname{Pr} P$ in infected and uninfected mink and ferrets.

\footnotetext{
IS.B. Prusiner. Science 216,136(1982)
}

${ }^{2} \mathrm{M}$. Scott. et al Cell 59.847 (1989)

\section{303 Direct Interaction of Human TFID with the HIV-1 Transactivator Tat}

John N. Brady, Graziella Piras, Michael F. Radonovich

Janet F. Duvall, Ali Fattaey* and Fatah Kashanchi

Laboratory of Molecular Virology, National Cancer Institute,

National Institutes of Health, Bethesda, MD 20892;

*Massachusetts General Hospital Cancer Center, Building 149,

13th Street, Chariestown, MA 02129

The Tat gene of human immunodeficiency virus (HIV) plays a central role in the activation and life cycle of HIV. The mechanism by which Tat exerts its effects has been observed both at the level of transcriptional initiation and elongation. The transactivation response element of Tat, TAR RNA, is located between residues +19 to +44 . Interestingly, even with the difference in nucleic acid specificities, Tat and DNA responsive acidic activators may act on a similar step in the transcriptional process. Here we report that Tat binds directly to the basal transcription factor TFIID. The transcriptional activity of HeLa extracts was depleted after chromatography on Tat af finity columns that specifically retained the transcription factor TFIID. TATA binding protein (TBP), expressed in and purified from $E$. coli, binds to Tat, suggesting that Tat interacts with the basic subunit of TFIID. Peptide competition analysis demonstrates that the conserved region of the $T$ at protein, amino acids 36 to 50 , mediates the Tat-TFIID interaction. Our novel results suggest that Tat may transduce upstream and downstream regulatory signals by direct interaction with the basal transcription factor TFIID. 
M 304 CELL-TO-CELL TRANSMISSION OF HIV INFECTION INDUCES TWO DISTINCT PHASES OF VIRAL RNA EXPRESSION UNDER SEPARATE REGULATORY CONTROL Christopher Burrell ${ }^{1} \cdot 2$, Tuckweng Kok ${ }^{1}$ and Peng Li', 'National Centre for HIV Virology Research, IMVS and 2Department of Microbiology and Immunology, The University of Adelaide, Frome Road, Adelaide SA 5000 , Australia

A laboratory clone of cells persistently infected with HTLV-IIIB (H3B cells) contained mainly the multispliced $(2 \mathrm{~kb})$ and singly spliced $(4.3 \mathrm{~kb})$ species of HIV RNA. When H3B cells were co-cultured with susceptible HUT78 celis. cell fusion occurred within $4 \mathrm{hr}$ of cell mixing, accompanied by a marked increase of only the unspliced, full length $(9.2 \mathrm{~kb}) \mathrm{HIV}$ RNA. This first phase of viral RNA induction (4-12 hr post infection) was followed by a second phase of viral RNA synthesis from $24 \mathrm{hr}$ post infection which consisted of significant increases in all three species of HIV RNA. Reverse transcriptase (RT) inhibitors, at concentrations which abolished de novo HIV DNA synthesis, abolished the first phase but not the second phase of viral RNA synthesis in our model system. A comparable one-step cell-free virus infection showed a similar pattern of viral RNA synthesis to that of the cell-to-cell transmission infection. However, viral RNA synthesis following cell-free virus infection was totally inhibited by RT inhibitors. The early phase (4-12hr) of $9.2 \mathrm{~kb}$ HIV RNA expression is likely to use newly synthesized HIV DNA as template; during this phase, both HIV RNA and DNA synthesis occur simultaneously, with each process dependent on the other for maximal yieid. The later (24-48hr) phase that comprises all 3 HIV RNA species, may be transcribed at least in part from proviral DNA from the original donor cells. This later phase may underline one of the mechanisms for natural spread of virus to new cells, and for enhanced viral gene expression in vivo, despite the presence of AZT.

M 306 A NOVEL INDUCIBLE EXPRESSION SYSTEM FOR THE HIV-1 REGULATOR OF VIRION EXPRESSION (reV) IN MAMMALIAN CELLS.

N. J. Clark and P. E. Stephens. Celltech Ltd. 216 bath Road, Slough, SL14EN, England.

CHOL76 th cells [2], have been stably transfected with a LAP expression vector and a cell line LAP72 which constitutively expresses LAP has been isolated. Labow et al. [1] have converted the lac repressor into a mammalian transcriptional activator. The lac activator protein (LAP) fusion is a potent activator of lac operator sequences and is strongly intibited by IPTG. A rev expression vector under the influence of three $L a C$ operators has been stably transfected in LAP72 cells. rev expression is induced when media containing IPTG is removed from the cells The regulation of rev expression appears to be tightly regulated as determined by Western and Northern analysis. A 15-25 fold induction in the expression of a reporter gene, Tissue Inhibitor of Metalloproteinases (TIMP) also under the control of three LaC operators was observed when LAP72 cells were grown in the absence of IPTG. Low levels of TIMP expression were detected in cells grown in the presence of IPTG. This inducible regulatory system will help elucidate the mechanism by which rev regulates HIV-1 envelope expression

[1] Labow M.A., Baim S.B., Shenk T., and Levine A.J. (1990). Mol. Cell. Biol. 1 0-7,3343-3356.

[2] Cockett M.I., Bebbington C.R., and Yarranton G.T. (1990) Nucleic Acids. Res. 1 9-2: 319-325.
M 305 HIV-1 RNA EXPRESSION BY FOUR CHRONICALLY INFECTED CELL LINES INDICATES MULTIPLE MECHANISMS OF LATENCY, Salvatore Butera, Beverly Roberts, Lee Lam*, Thomas Hodge*, and Thomas Folks, Retrovirus Diseases Branch, Division of Viral and Rickettsial Diseases, "Immunology Branch, Division of HIV/AIDS, Centers for Disease Control, Atlanta, Georgia 30333

HIV-1 latency at a cellular level has recently been described as a state of nonproductive expression controlled by selective viral RNA splicing. To test the universality of this observation, we compared the HIV-1 RNA partems in four chronically infected cell lines (U1, promonocytic; ACH-2, T-lymphocytic; OM-10.1, promyelocytic; and J1.1, T-lymphocytic). As previously reported, noninduced $\mathrm{U1}$ and $\mathrm{ACH}-2$ cultures displayed a nonproductive HIV-1 RNA pattern dominated by the spliced messages with little full-length message being evident. However, noninduced OM-10.1 and $J 1.1$ cultures showed an HIV-1 RNA pattern wherein the full-length message was clearly represented; a pattern reminiscent of productive viral expression. In OM-10.1 cultures, this productive RNA pattern appeared to be contributed only by a small constitutively expressing population of cells. Thus, reverse transcriptase-dependent polymerase chain reaction (RT-PCR) and limit dilutional analysis were performed to determine the cellular frequency of expressed viral RNA Greater than $20 \%$ of noninduced U1 and ACH-2 cells contained detectable messages of the multiply spliced RNA species, again indicating nonproductive expression during latency. In sharp contrast, onily $2 \%$ of noninduced OM-10.1 and J1.1 cells contained detectable HIV-1 messages, therefore representing models of absolute latency under alternative mechanisms of control. All four cell lines responded to TNF- $\alpha$ induction by initially accumulating the multiply spliced viral RNA messages which then gave rise to an increase of all viral RNA species, thereby supporing the Rev threshold theory. Although the accumulation of multiply spliced viral RNA species after induction appears universal for the conversion to productive viral expression, these results clearly demonstrate that mechanisms beyond aberrant RNA splicing may control the state of nonproductive HIV-1 expression.

\section{307 REVERSE TRANSCRIPTION DOES NOT OCCUR} WHEN FRESHLY ISOLATED MONOCYTES ARE INFECTED WITH HIV. Crowe Suzanne*, Maerz Anne*, Uren Sandra $^{+}$, Violo Antoinette ${ }^{+}$, Chang David ${ }^{+}$, Boyle William ${ }^{+}$, Sonza Secondo*. "AIDS Pathogenesis Research Unit, Macfarlane Burnet Centre for Medical Research. Melbourne, 3078. Microbiology Department, University of Melbourne. Parkville, 3052.

The majority of freshly isolated monocytes express high levels of CD4. Following overnight incubation the level of CD4 expression decreases dramatically, and then slowly increases over the next 2-3 weeks in culture. There is a poor, even paradoxical, relationship between $\mathrm{CD} 4$ expression and susceptibility of monocyte/macrophages to HIV infection. Using 2 isolates of HIV (DV, \& Ba-L), freshly isolated monocytes appear to be refractory to HIV infection, although 7 day cultured cells from the same donor, which have considerably less CD4 expression, are fully permissive. Using primer pairs to amplify the 100 b.p. of the 5'LTR region which is reverse-transcribed early (U3-LTR), mid length (vif/vpu) and full length (gag SK, 38-39) transcripts, there was no CDNA detected in monocytes infected with HIV on the day of isolation, for up to 7 days following infection. Mid-length transcripts were detected within 24 hours in cells infected 1 day post isolation. cDNA was easily amplified by all primer pairs within 24 hours of infection from cells infected on the third and subsequent days in culture. These data suggest that there is a block in HIV replication in fresh monocytes occurring either at the level of reverse transcription or at an earlier stage within the replicative cycle of HIV. 
M 308 FUNCTIONALROLESOFHIV-1 GLYCOPROTEINS GLYCANS. E. Fenouillet, I. M. Jones*, JC Gluckman. CNRS URA1463 Paris; Instit. of Virology*. Oxford.

Glycans (CHO) of HIV-1 env precursor gp 160 represent $50 \%$ of its $\mathrm{MW}$. Its cleavage products, gp 120 and gp 41 , are responsible for HIV tropism to CD4+ cells and for membrane fusion, respectively.

Using an inhibitor of a-glucosidases (dNJ) which leads to abnormal glycosylation, we showed that $\mathrm{CHO}$ clusters of gp 160 induce, during biosynthesis, the folding and bioactive conformation of gp120: i) the interaction between CD4 and dNJ-abnormally glycosylated gp 120 was altered ii) the accessibility of the $V 3$ loop, a region of gp 120 that plays a key role in membrane fusion process, is diminished. Such modified properties could account for the impairment of HIV-1 infectivity by dNJ

Mutation of gp4t cluster of CHO sites inhibited gp160 cleavage and modified the conformation of gp120 expressed on uncleaved gp 160. Despite expression of bioactive gp120 at the cell surface, membrane fusion was also completely abolished.

In contrast, after biosynthesis, $\mathrm{CHO}$ present on mature viral gp120 and gp41 are involved neither in their bioactivity nor in their immunoreactivity. Binding to CD4 of enzymatically deglycosylated gp 120 is not modified and the ability of deglycosylated virus to bind to and to infect CD4+ cells is reduced by only 10 fold.

Therefore, CHO are necessary to create but not to maintain the functional conformation of envproducts
M 309 RNASE D ACTIVITY ASSOCIATED WITH HN-1 REVERSE TRANSCRIPTASE DISPLAYS THE SAME CLEAVAGE SPECIFICITY AS E.COLI RNASE III, Zdenek Hostomsky, Geoffrey Hudson, Soheil Rahmati and Zuzana Hostomska, Agouron Pharmaceuticals, Inc., San Diego, CA 92121

RNase D was recently reported as a new enzymatic activity associated with HIV-1 reverse transcriptase (RT), cleaving RNA at two positions within the double-stranded region of the tRNA primer - viral RNA template complex (Ben-Artzi et al, Proc. Natl. Acad. Sci. USA 89 (1992) 927-931). This would make RNase $\mathrm{D}$ a fourth distinct activity of HIV-1 RT, in addition to RNAand DNA- dependent DNA polymerase, and RNase $H$. Using a specific substrate containing $\mathrm{tRNA}$ Lys,3 hybridized to the primer binding site, we were able to detect the reported RNAse D activity in our preparations of recombinant HIV-I RT. This activity was also present in several active-site mutants of $R T$, suggesting that it is independent of the RNase $\mathrm{H}$ and polymerase functionalities of RT. Furthermore, we found that the cleavage specificity of $R$ Nase $D$ is the same as that of RVase III isolated from E. coli. A likely explanation of these results that the observed RNase D activity is attributable to traces of RNase III contamination - was further strengthened by the finding that the recombinant preparations of HIV-I RT can specifically cleave a phage T7-derived double-stranded RNA processing signal, which has been used as a model substrate for detection of $E$. coli RNase III. Moreover, RT purified from an RNase III- strain of $E$. coli displayed no cleavage of the tRNA primer - RNA template complex.
M 310 THE IN VIVO ROLE OF CREB $\alpha$ ON HTLV-1 AND BLV PROMOTERS, Endre Kiss-Toth, Ildiko Unk, Imre Boros, Institute of Biochemistry. Biological Research Center, Hungarian Academy of Sciences, 6701 Szeged, P.O.B. 521. Hungary

A large body of evidence has accumulated confirming that the CRE-like elements, present in both the HTLVI and BLV LTRs, may play an important role in the activation of these virus promoters. (These mechanisms are coordinated by the virus trans-activator protein called TAX.) We used transient expression system to study the activity of CREB $\alpha$ (the protein can bind the CRE element) on the retrovirus promoters. We found that CREB $\alpha$ didn't activate the virus promoters, instead it strongly reduced the degree of TAX dependent activation. Deletions and point mutations of CREB $\alpha$ were constructed to study the molecular mechanism of the CREB $\alpha$-TAX interaction. We got the following data:

1. Deletions and point mutations in the $\mathrm{N}$-terminal of CREB ${ }_{\alpha}$ abolished the "inhibitor" activity of the protein.

2. Deleting 145 amino acids in the C-terminal -containing the Leu-zipper and the DNA binding domain- the decreasing effect was preserved.

3. The expressed phosphorilation site of the protein didn't change the TAX dependent activation. These data suggest, that not the limited number of protein Kinase $A$ is the reason of the inhibitory effect of CREB $\alpha$.

On the basis of these results we concluded, that $\mathrm{CREB}_{\alpha}$ can interact with both the CRE-like elements and the TAX protein but it is not involved in the active transcriptional initiation complex. In our hypothesis not the CREB ${ }_{\alpha}$, rather another member of the ATF CREB family plays active role in the trans-activation in vivo. CREB $\alpha$ may work as a competitor in these processes. Experiements confirming this hypothesis are in progress.
M 311 MOLECULAR BASIS OF A BARRIER TO AUTOINTEGRATION OF MOLONEY MURINE LEUKEMIA VIRUS DNA, Myung Soo Lee, Kiyoshi Mizuuchi and Robert Craigie, Laboratory of Molecular Biology, National Institute of Diabetes and Digestive and Kidney Diseases, National Institutes of Health, Bethesda, MD 20892

As an essential step in the retrovirus life cycle, retroviral DNA integrates into the host genome. It is important for the retrovirus to ensure that the viral DNA does not integrate into itself (termed auto-integration), a process that would result in suicide of the virus in the infected cell. What is the mechanism that prevents auto-integration of the retroviral DNA?

Retroviral DNA integration is mediated by a nucleoprotein complex [termed the integration-competent nucleoprotein complex (INC)]. The INC, isolated from cells after infection with Moloney murine leukemia virus, efficiently integrates its endogenous copy of viral DNA into an exogenously introduced target DNA in vitro. Utilizing preparations of isolated INCs, we have developed a simple assay to detect auto-integration of the retroviral DNA into itself and discovered that the degree of the auto-integration can be modulated by the ionic strength of the reaction mixture. In the presence of $\mathrm{KCl}$ at $500 \mathrm{mM}$ the auto-integration reaction is highly preferred to the intermolecular reaction, whereas the products are almost exclusively intermolecular when reactions are performed at lower ionic strength. Auto-integration events also predominate when the INC is preincubated with high salt and the reaction is subsequently carried out at low ionic strength. This suggests that the high ionic strength causes a change in the organization of the INC that disrupts a barrier to auto-integration. The autointegration complex has a lower $S$ value than the intact INC, indicating that high salt treatment results in a less compact structure and/or loss of protein components. We are investigating the structural organization and protein composition of these two classes of complex to identify the features of the intact complex that prevent auto-integration. 
M 312 MULTIPLE SEQUENCE ELEMENTS WITHIN THE HTL V-I LTR CONTRIBUTE TO MAXIMAL

TRANSACTIVATION BY TAX. Susan J. Marriott and Laurie M Connor, Division of Molecular Virology, Baylor College of Medicine. Houston. TX 77030.

The $\mathrm{Tax}_{1}$ protein of the human $T$ cell leukemia virus (HTLV-I) is a

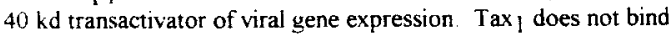
directly to DNA rather, it associates indirectly with DNA via cellular transcription factors. To further investigate the activation of HCLV-I transcription by $T_{a x}$, a chimeric protein containing Tax 1 fused to the DNA binding domain of Gal4 was created (Gal4Tax 1 ). HTLV-I LTR reporter plasmids were constructed in which specific $\operatorname{Tax}_{1}$ responsive elements were replaced with $\mathrm{Gal} 4$ binding sites. Cotransfection of Gal4-Tax 1 or $\operatorname{Tax}_{1}$ with HTLV-I LTR reporter constructs containing Gal 4 binding sites demonstrated that Gal4 sequences were necessary for maximal activation of the promoter by Gal4-Tax 1 . However, sequences surrounding the Gal4 binding sites were important in determining the level of Gal4 $\mathrm{Tax}_{1}$ activation. Association of Gal4-Tax 1 with promoters which contained Gal4 binding sites, but which lacked flanking LTR sequences. did not support maximal Gal4-Tax 1 transactivation. LTR-CAT reporter constructs containing Gal4 binding sites flanked by two 21 base pair repeat elements demonstrated a 78 -fold greater response to Gal4-Tax 1 than those which lacked flanking 21 base pair elements. The results of these studies suggest that cellular transcription factors which bind the 21 base pair repeats directly influence the ability of $\operatorname{Tax}_{1}$ to function as a transactivator and that this influence is not solely due to the indirect association of $\operatorname{Tax}_{1}$ with those elements.
M 313 STEADY-STATE KINETIC CHARACTERIZATION OF A RECOMBINANT RNASE H-DEFICIENT HIV-1 REVERSE TRANSCRIPTASE MUTANT, Laura K. Moen and Thomas S. Heard, Dept. of Chemistry and Biochemistry, Old Dominion University, Norfolk, VA 23529

HIV reverse transcriptase (E.C.2.7.7.49) is a primary target for chemotherapy because it is a viral enzyme required for viral replication. Thought to exist in vivo as a heterodimer of $M_{A}$ 121,000, HIV reverse transcriptase (HIV RT) has two functional domains: the polymerase domain catalyzes the replication of double-stranded DNA from single-stranded RNA; the RNase $H$ domain catalyzes cleavage of RNA in RNA-DNA hybrids.

The polymerase domain is physically located in the $\mathrm{N}$-terminal region of HIV RT and the RNase $H$ domain is at the C-terminal region. Although the two domains are physically and functionally distinct (DeStefano, et al., 1991, J. Biol. Chem.), experimental evidence from this lab and others suggests that the two domains share a nucleic acid binding region (Moen, et al., 1992, AlDS Res.)(Krug and Berger, 1991, Biochem.). This evidence is supported by the recently reported crystal structure of HIV RT (Kohlstaedt, et al., 1992, Science).

Work in this laboratory has focussed on the effects of a 23 amino acid C-terminal deletion. This recombinant mutant has wild-type polymerase activity but has no detectable RNase $\mathrm{H}$ activity, and earlier work in this lab suggested that the 23 amino acid deletion may have affected the polymerase mechanism itself (Moen, et al., 1992, AIDS Res.). Recently, we have completed a steady-state characterization of our mutant. Although the mechanism is still a sequential ordered bisubstrate reaction, we have found that the C-terminal deletion has decreased the affinity for its nucleic acid substrate as judged by the $K_{M}$ for primer-template. Furthermore, this decrease in affinity results in a more distributive mechanism of polymerization. Since processivity is related to fidelity (Bebenek, et al., 1989, J. Biol. Chem.), our results may mean that RNase $\mathrm{H}$ inhibitors will increase replication errors by HIV RT. This work was supported by PHS Grant Al29311 to L.K. Moen.
M 314

CELLULAR COFACTORS IN HIV-1 TAT-MEDIATED TRANS-ACTIVATION Michael Newstein, Im-soon Lee, and Peter R. Shank. Brown University Division of Biology and Medicine, Providence, RI, USA

The Tat gene product is a potent positive regulator of HIV LTR expression which is required for virus replication. A novel aspect of Tat trans-activation is the physical association of the Tat protein with its cis. responsive element, TAR (Trans-acting response) RNA. However, a precise mechanistic explanation of Tat mediated trans-activation and the role of the TAR sequence are currently lacking.

Our work focuses on the role of cellular factors in the process of Tat mediated trans-activation. We have found that rodent cells are relatively refractory to Tat transactivation as compared to human cells because they lack species-specific cellular factor(s). We have determined that human chromosome 12 encodes a factor which greatly enhances HIV-1 Tat mediated trans-activation of the HIV-1 LTR.

We have utilized chimeric Tat proteins containing heterologous RNA binding domains to study the role of the Tat-TAR interaction and cellular factors in the process of Tat mediated trans-activation. Our data suggest that TAR RNA interacts with both cellular factors and Tat to form a ribonucleoprotein complex which mediates trans-activation. The failure of Tat to function efficiently in rodent cells may be due to the lack speciesspecific TAR associated factors. A model for the role of cellular factors in Tat mediated trans-activation is discussed.

\section{315 THE DETECTION AND ANALYSIS OF NATURAL ANTI- SENSE MESSAGE IN HTLV-I INFECTED, T-CELIS} AND PATIENTS - POSSIBLE ROLE FOR RNA REPLICASE, Baishali B. Paul 1,2 , Syamalima Dube ${ }^{2}$, Virginia Bryz-Gornia ${ }^{2}$, John Sninsky, Christine Stephens ${ }^{2}$, Dipak K. Dube', and Bernard J. Poies $z^{1,2}$, Depts. of Microbio./Imm. and Med., SUNY-HSC, Syracuse, NY 13210; ${ }^{3}$ Cetus Corp., Emeryville, CA 94608 classically, human retroviruses are believed to express only positive $(+)$ sense messages. Using the enzyme, Tth, and various primers in sequential fashion, we have been able to detect both + and negative $(-)$ strand HTLV-I transcripts in DNAse-treated, poly a RNA from HTLV-I infected Tcells via RT-PCR. Both genomic and spliced + and - strand messages were detected. No RT-PCR products were observed if the target samples were first treated with RNAse, if neither primer was initially added during the RT step. Presence of - strand HTLV-I messages was further confirmed by Northern blot analyses using a series of strand-specific probes. Further, we find that HTLV-I infected T-cells have both + and - strand human B-actin mRNA, whereas in uninfected human $T$-cells only + strand B-actin message was detected. More importantly using RT-PCR we have been able, for the first time, to detect the in vivo presence of HTLV-I negative strand messages in the fresh PBM's of three HTLV-I infected patients. Interestingly, the size and sequence of genomic and spliced, + and - strand messages were found to be similar and approximate comple-ments of each other respectively, thereby demonstrating a similar splicing pattern in + and spliced messages. Further, the absence of any template DNA copies corresponding to the spliced sequences and the above observations suggest that the anti-sense messages must be transcribed directly from corresponding + strand messages. This and other preliminary data suggests to us the presence of a virally encoded or induced RNA dependent RNA polymerase in HTLV-I infected cells. 
M 316 MODULATION OF HIV-1 REPLICATION BY CYTOXINES: MOLECULAR MECHANT6M, Paula $\mathrm{K}$

Pitha, Yasaman Bhirazi, and Waldemar Popik, The Johns Hopkins oniversity oncology Center, Baltimore, MD 21231 our interest is in the molecular mechanisms by which cytokines affect replication of human immunodeficiency virus type 1 (日IV-1). We have shown that interferon-a (IFN) markedy inhibits HIV-1 replication in a T cell line, cem174, as well as in peripheral blood mononuclear cells (PMBC) in a single replication cycle and that the effect is on the preintegrational step. Recently, we have demonstrated that the IFN block occurs at the level of provirus formation. In IFN-treated cells, formation of both early and late proviral DNA is inbibited, suggesting that IFN inhibits initiation of reverse transcription. The inhibition of provirus formation mediated by the virion-associated or recombinant HIV-1 reverse transcriptase by extracts from IFNtreated cells could also be demonstrated in vitro. Identification of the nature of the inhibitory component in IFN-treated cell extracts is in progress.

In contrast to IFN, tumor necrosis factor (TNF) $-\alpha$ upregulates expression of HIV-1 provirus in $T$ cells and monocytes by activation of nuclear factors binding to the $\mathrm{NF}-\mathrm{KB}$ sequences of HIV-1 LTR. The TNF- $\alpha$-mediated transactivation is Tat independent. We have recently found that TNF- $\alpha$ can complement the tat effect and activate expression of the latent, tat defective HIV-1 provirus in $T$ cells and support its replication in PMBC. While the TMP- $\alpha$ stimulates the rate of HIV-1 provirus transcription, unlike Tat, it does not reduce transcriptional polarity. surprisingly, different patterns between viral protein precursor and virion protein synthesis were observed when HIV-1 provirus was activated with TWF- $\alpha$ or rat.

M 318 INCREASED EXPRESSION OF PTP PROTEIN DURING DIFFERENTIATION OF MURINE EMBRYONAL CARCINOMA CELLS, Suzette A. Priola and Bruce Chesebro, National Institutes of Health, National Institute of Allergy and Infectious Diseases, Laboratory of Persistent Viral Diseases, Rocky Mountain Laboratories, Hamilton, MT 59840

The transmissable spongiform encephalopathies (TSE) are a group of infectious neurodegenerative diseases which include scrapie of sheep bovine spongiform encephalopathy of cattle, and kuru, GerstmannStraussler syndrome and Creutzfeldt-Jakob disease of humans. The causative agent in unknown. An abnormal form of PtP, a cell surface glycoprotein present in a wide variety of tissues including brain, heart and lung, is associated with disease pathogenesis in the TSEs. The normal function of PrP is unknown. PrP is expressed at low levels in P-19 cells, an embryonal carcinoma cell line that can be induced to differentiate into extra-embryonic endoderm cells, neurons or cardiac and skeletal muscle cells when aggregated in media alone, or in the presence of retinoic acid (RA) or dimethyl-sulfoxide (DMSO), respectively. Aggregation of P-19 cells in the presence of RA, DMSO or media alone led to a stable increase in both PrP mRNA and protein. Increased levels of PrP mRNA and protein were not observed in the absence of morphological changes, indicating that PTP may function either in the differentiation process itself or as a protein whose function is necessary in the new cell phenotype.
M 317 ENCAPSIDATION OF CHIMERIC HIV-1-POLIOVIRUS MINIREPLICONS, Donna C. Porter, David C. Ansardi, Weon S. Choi, and Casey D. Morrow, Department of Microbiology, University of Alabama at Birmingham, Birmingham, AL 35294

Previous studies have determined that the entire poliovirus genome is no required for RNA replication. Naturally occuring defective interfering particles (DIs) of poliovirus have been discovered which have partial deletions of the $P l$ capsid region that maintain the translational reading frame and capacity for replication. Based on this, we substituted foreign, nonpoliovirus sequences into the poliovirus genome to further explore the requirements for replication and encapsidation of the genome. Recently, we have described the construction and characterization of chimeric HIV-1poliovirus genomes in which the gag and pol genes of HIV-l have been substituted for the capsid genes of poliovirus. Transfection of these RNAs into tissue culture cells results in replication of the RNA genome and expression of HIV-1-Pl fusion proteins. Here, we report on the encapsidation and amplification of the mini-replicons to obtain sufficient quantities for biological characterization. In order to do this, the chimeric HIV-l-poliovirus genomes were transfected into cells previously infected with a recombinant vaccinia vinus (VV-P1) which expresses the poliovirus capsid precursor protein, P1. The chimeric RNA genomes replicated and expressed the appropriate HIV-1-PI fusion proteins as determined by immunoprecipitation with anti-HIV-1 antibodies. To detect encapsidation of the mini-replicons, the encapsidated genomes were purified from cells by ultracentrifugation. Re-infection of cells with the purified encapsidated chimeric RNA genomes resulted in expression of the HIV-?-Pl fusion proteins. Serial passages of the encapsidated chimeric HIV-1-poliovirus genomes was accomplished by co-infecting cells with the encapsidated mini-replicons and VV-P1. Northern blot analysis revealed that no significant deletions of the chimeric genomes occured during serial passages to generate high titre stocks. Also, the encapsidated mini-replicons were neutralized by anti-poliovirus antibodies indicating that the chimeric genomes were encapsidated into poliovirions. The results of this study demonstrate the feasibility of using poliovirus as an expression system and establish a means to further characterize the requirements for replication and encapsidation of poliovirus.

M 319 INTERACTION OF LYMPHOCYTE / MONOCTYE- AND NEURAL CELL-DERIVED FACTORS WITH THE HTLV-I TAX-RESPONSIVE ELEMENTS; Maribeth Tillmann and Brian Wigdahl, Department of Microbiology and Immunology, The Pennsylvania State University College of Medicine, Hershey, PA 17033.

Human T-cell leukemia virus type I, an etiologic agent of adult $T$-cell leukemia (ATL) and a chronic neurologic disorder (TSP), encodes a trans-activating protein, Tax. Tax is capable of transcriptionally transtrans-activating protein, Tax. Tax is capable of transcriptionally trans-
activating HTL V-I by interacting with specific sequences in the HTLV-I long terminal repeats (LTRs). These sequences comprise an inducible enhancer containing three imperfect tandem repeats of a 21 bp sequence. Evidence suggests that Tax is incapable of directly interacting with DNA. Therefore, Tax most likely exerts its effects via interaction with cellular factors resulting in transcriptional activation. Characterization of the cellular factors which interact with the 21 bp repeats is essential to understanding the molecular mechanisms involved in Tax-mediated trans-activation and possibly in the cellular tropism of HTLV-I. We are currently investigating the interaction of nuclear factors derived from cells of lymphoid, monocytoid and neural cell origin with each of the three Tax-responsive 21 bp repeats. Utilizing the mobility shift DNAbinding assay, we have detected several differences in the DNA-protein complexes formed between the 21 bp repeats and nuclear factors derived from various cell lines. Nuclear extracts derived from cells of lymphoid (Jurkat, SupT1), monocytoid (U937), neuronal (IMR-32, SK-N-MC), and glial (U373-MG) cell origin were reacted with each of the three 21 bp repeats. Both specific and non-specific DNA-protein complexes were detected when each of the 21 bp repeats were reacted with the nuclear extracts. A unique DNA-protein complex was detected when nuclear extracts derived from IMR-32 and U373-MG cells were reacted with the middle $21 \mathrm{bp}$ repeat. This complex was not detected in assays performed with the remainder of the nuclear extracts examined. Furthermore, one of the specific DNA-protein complexes detected when the nuclear extracts derived from Jurkat, SupT 1, U937, IMR-32, and SK-N-MC cell lines were reacted with each of the three 21 bp repeats was not detected when nuclear extracts derived from U373-MG cells were similarly assayed. The nature and relevance of the putative neural cell-specific DNA-protein complexes are currently under investigation. 
M 320 FUNCTION OF EXON 2 OF TAT-2 IN TRANS-ACTIVATION OF HIV-1 AND HIV-2 LONG TERMINAL REPEATS. Sandra E. Tong. Barbara Porton, and Jun Pagtakhan. UCSF, Dept. of Med., SF VAMC. San Francisco. CA 94121

HIV -1 and HIV -2 are human retroviruses that differ in asymptomatic periods of latency but cause identical immunodeficiency syndromes. AIDS. High level expression of HN-1 is dependent on a viral upregulatory protein. Tat (trans-activat or of transcription)-1, which acts on the trans-acting responsive region (TAR) - 1 transcribed from positions +1 to +60 in the HIV-1 long terminal repeat (LTR). TAR-1 forms a single stem-loop secondary RNA structure. High level expression of HIV-2 also requires its trans-activator, Tat-2; however. the TAR- 2 region $(+1$ to +125 in the HIV-2LTR) forms a double stemthe TAR-2 region $(+1$ to +125 in the 1 . -2 TR) loms a double stem. the Jurkat cell line. Previous investigators found that Tat-2 the Jurkat cell line. Previous investigators found that Tat-2 the HIV-1LTR. We find, however, that Tat-2 trans-activates the single stem loop of HIV-1LTR by 110 -fold when the two exons of tat-2 are expressed in the cDNA form. Trans-activation of the HIV-1LTR is decreased (32-fold TA) when the genornic form of tat-2 is co-

transfected: titration studies show that TA increases with increasing amounts of plasmid expressing genomic tat-2. Trans-activation of the HIV-1LTR is also markedly decreased (11-fold TA) when only the first exon (encoding 99 a.a.) of tat-2 is expressed. In contrast to genomic tat-2. however, titration studies show that TA does not increase with increasing amounts of plasmld expressing exon 1 of tat-2. This finding suggests that genomic tat-2 is only partially spliced and expresses both an inefficient Tat -2 from exon 1 and an efficient full-length Tat-2. The product of the first exon of tat-2 trans-activates the HIV-2LTR (80-fold TA). The genomic form of tat2 has intermediate effects (104-fold TA) and full-length Tat-2 transactivates HIV-2 LTR most efficiently (350-fold TA). Mutagenesis studies suggest that basic residues in exon 2 of Tat -2 are required for optimal trans-activation of HIV-1 and HIV-2 LTRs. Thus, genomic tat -2 appears to be spliced inelficiently. The 31 carboxy-teminal amino acids encoded by the second exon of tat-2 allows this transactivator to function like Tat- 1 and to overcome the requirement for a double stem-loop. A domain(s) encoded by the second exon, such as the basic domain. may stabilize the interaction between TAT and cellular proteins in the transcription initiation complex with the HN-1LTR.

\section{Late Abstracts}

THE HEPATITIS B VIRUS $p X$ PROTEIN CAN EXERT ITS TRANSACTIVATING POTENTIAL IN VIVO. $C$. Balsano^^, O. Billet^, M. Bennoun^, C. Cavard^, A. Zider^, G. Grimber^, G. Natoli^,P. Briand^ M. Levrero* * Fond. A. Cesalpino - I Clinica Medica Rome - Italy; AI.C.G.M. - INSERM - Paris France

Most if not all the evidences provided so far on HBV $\mathrm{pX}$ induced transactivation have been obtained in immortalized or transformed cells transfected with high amounts of $\mathrm{pX}$ expression vectors. Thus, in order to evaluate whether $\mathrm{px}$ is able to modulate gene expression in vivo and in normal hepatocytes, we generated transgenic mice carrying the $X$ ORF under the control of the human antithrombin III (ATIII) gene regulatory region. These mice express the $16 \mathrm{Kd} p x$ protein in the liver, as demonstrated by immunoprecipitation, in the kidney, the lung and the gut. Cross-breeding of $\mathrm{pX}$ mice with transgenics carrying either the Lac-z or the chloramphenicol acetyl transferase (CAT) bacterial reporter gene driven by the HIV1LTR allowed us to demonstrate, for the first time, the in vivo transactivating function of $\mathrm{px}$. Expression of $\mathrm{pX}$ in the liver and the lung stimulates the HIV1-LTR driven expression of both Beta-galactosidase and CAT in the double transgenic mice. No increase in reporter genes expression was observed in tissues, such as spleen, brain and hearth, that do not express pX. The transactivation phenomenon was maximal in the post-natal period, thus suggesting the possible requirement of developmentally regulated cofactors. Several lines of evidence suggest that the kB-like enhancer elements present in the LTR mediate $p x$ transactivation. Using in vitro DNA/protein interaction assays, we could demonstrate that both $p X$ expressing Hepg2 cells and liver cells derived from $p X$ transgenics display an increased binding activity of NFkB or $\mathrm{KB}-1$ ike transcription factors.
THE HUMAN CYTOMEGALOVIRUS UL97 GENE PRODUCT: A PROTEIN

KINASE HOMOLOG ESSENTIAL TO THE ANTIVIRAL ACTIVITY OF

GANCICLOVIR. Karen K. Biron, Wettcome Research Laboratories, 3030 Cornwallis Road, Research Triangle Park, NC 27709.

Ganciclovir is a major therapeutic agent for the treatment of HCMV infections in patients with AIDS. Ganciclovir resistant virus has been recovered from AIDS patients whose CMV disease progressed after prolonged ganciclovir therapy. The biochemical basis for the resistance in a majority of these CMV strains is the inability to induce the intracellular anabolism of ganciclovir in virus-infected cells (Stanat et. al. Antimicrob. Ag Chemo. 35; 2191, 1991). This ganciclovir-resistance phenotype of a laboratory mutant has been genetically mapped to the UL97 open reading frame in the CMV genome (Sullivan et. al., Nat. $\underline{358}$; 162, 1992). The $78 \mathrm{kD}$ predicted product shares homologies with the catalytic regions of protein kinases, and with guanylyl cyclase and the bacterial aminoglycoside phosphotransferases. The function of this protein in the replication or pathogenesis of HCMV has not been determined. Analyses of the UL97 protein synthesized in cells infected with ganciclovir-sensitive and resistant strains recovered from AIDS patients indicates that full length polypeptide is induced by alf nine strains examined. Sequence data for the UL97 genes of ganciclovir sensitive and resistant isolate pairs will be presented. 
STRATEGIES FOR THE DISCOVERY OF ANTI

INELUENZA AGENTS C Laughlin, Antiviral Research Branch, National Institute of Allergy and Infectious Diseases, 6003 Executive Blvd., Rockvilie, MD, 20852, USA

Amantadine was the first parenteral antiviral agent to be approved by the United States Food and Drug Administration. Since this event in 1966, multiple other antiviral therapies have been approved, yet amantadine remains the only available antiviral therapy for influenza. The properties of amantadine will be briefly reviewed. Specific steps in the replication and pathogenesis of influenza will be discussed as possible targets for intervention. Several novel experimental antiviral agents which interact with some of these targets will be discussed.
MODIFICATION OF AP-1 TRANSCRIPTION FACTOR FUNCTION INDUCED BY THE TRANSIENT EXPRESSION OF THE HEPATITIS B VIRUS TRANSACTIVATOR $p X$. G. Natoli, M.L. Avantaggiati. C. Balsano, P. Chirillo, M. Artini, P. Costanzo, M. Levrero. Fond. A. Cesalpino, I Clinica Medica. Univ. of Rome, Italy.

The hepatitis $B$ virus $X$ gene encodes a protein capable of transactivating gene expression from many cellular and viral promoters. To date, the mechanisms of the $\mathrm{pX}$ mediated trans-activation are poorly understood. We have evaluated the effects of a transient $p X$ expression on the function of APl, the heterodimer mainly composed by $c-J u n$ and $c-F o s$. $p x$ was able to activate the AP1-directed transcription in hepatic and nonhepatic cell lines. Anyway, among the different cell lines tested, only in HepG2 cells the AP1activation was found to be associated with an increase in the DNA-binding activity of the cJun/C-Fos heterodimer. The increased AP.L binding was not associated with an increase in the overall amount of c-Jun and c-Fos proteins and was not blocked by either calphostin $c$, sphingosine or HA1004, which are powerful pKC and pKA inhibitors respectively. On the other hand, staurosporine, a potent and non-specific proteinkinases inhibitor, blocked almost completely the pX-dependent increase in the API binding, thus suggesting the involvement of PKC- and PKAindependent phosphorylation events in the observed phenomenon. Preliminary results suggest that in cells different from Hepge pX can increase the transcriptional activation properties of c-Jun in a way similar to that observed for Ha-ras. The ability of px to activate API-responsive regulatory sequences could be relevant for both viral pathogenesis and for the development of hepatocellular carcinoma.
DRUG-DEPENDENT MUTANTS OF SABIN POLTOVIRUS TYPE 3. A. G. Mosser and R. R. Rueckert, University of Wisconsin-Madison, Madison, WI 53706

The WIN drugs and similar hydrophobic compounds that insert into the VPI beta barrel of picornaviruses have been shown to block viral uncoating. In order to identify portions of the viral capsid that function in uncoating, 22 spontaneous mutants of Sabin poliovirus type 3 were selected for drug resistance by plating on Hela cell monolayers in the presence of WIN 51711 . When replated in the presence and absence of drug, two classes of mutants were observed; 14 mutants displayed a drug-dependent phenotype and 8 were drug-resistant but not dependent. Non-dependent mutants plaqued with equal efficiency in the presence or absence of drug. Drug-dependent mutants made no plaques in the absence of drug except for revertants.

In single cycle growth curve experiments, arug dependent mutants grew as well in the absence of drug as in its presence. The paradoxical inability of dependent mutants to form plaques was traced to extreme thermolability at $37^{\circ} \mathrm{C}$ in the absence of drug; mutants lost $90 \%$ of their infectivity every minute. Thermolability was exhibited only after virus was released from the cell, implying the presence of a cell-associated protective factor. The thermodecay product was shown to consist of $135 \mathrm{~S}$ particles lacking VP4. Thus, when not stabilized by drug, these mutants appear to undergo the first stage in viral uncoating without interacting with cellular receptor. Identification of amino acid substitutions in the capsids of these mutants is currently underway.
A PROTEIN BEARING C-MYC ANTIGENICITY ACCUMULATES IN THE NUCLEI OF HEPATITIS DELTA ANTIGEN EXPRESSING CELLS. G. Natoli\#, F. Negro*, G. Tappero^, F. Rosina*, A. Smedile*, F. Bonino*, M. Rizzetto*, M. Levrero\#. \# Fond. A. Cesalpino, I Clinica Medica, Univ. of Rome, Italy. A Clinica Medica Generale, osp. S. Luigi orbassano, Turin. * Div. of Gastroenterology, osp. Le Molinette, Turin, Italy.

Patients with chronic but not acute hepatitis delta virus infection undergo a strong accumulation of a protein of cellular origin which specifically reacts with a panel of anti cmyc antibodies. The accumulation of this protein occurs in the same nuclei expressing the delta antigen and the phenomenon is reproducible in vitro after transfection of HBsAg positive and negative hepatoma cell 1 ines with HD-Ag expression vectors. In order to better characterize the phenomenon, we infected cells of hepatic and non-hepatic origin with recombinant vaccinia-viruses expressing the two forms of the delta antigen, $\mathbf{2} 24$ and p27. The accumulation of the c-myc related protein was in these conditions less strong than in vivo and in transfected cells, due to the negative effects of vacciniavirus infection on transcription of cellular genes. The different pattern of nuclear expression of $\mathrm{p} 24$ and $\mathrm{p} 27$ exactly corresponded to the different pattern of c-myc accumulation. In situ hybridization on cells transfected with HDAg expression vectors or infected with the vaccinia-viruses reveals that the accumulation of c-myc is not associated with an increase in the amount of the c-myc mRNAs. Moreover, delta antigen was unable to transactivate the c-myc promoter in CAT assay. The development of functional tests to study the c-myc function in HD-Ag expressing cells will allow to understand the significance of the phenomenon. 
THERAPEUTIC APPROACHES TO HERPES SIMPLEX VIRUS INFECTIONS, Richard J. Whitley, M.D., Earl R. Kern, Ph.D. University of Alabama at Birmingham,

Birmingham, AL 35294

Therapy of herpes simplex virus (HSV) infections of the central nervous system (CNS) are difficult to treat.

Current therapeutic approaches utilize the deployment of acyclovir for the management of these infections.

Acyclovir therapy decreases mortality from 708 in the

absence of treatment to approximately 28 \& 6 months after

therapy in older children and adults. Approximately 38

of treated individuals will return to normal function 2

years after treatment. These data indicate that, while

therapy is effective, significant improvement is

required. Newer therapeutic approaches have utilized

antiviral drugs in combination with human and humanized

monoclonal antibodies. Utilization of acyclovir and

humanized monoclonal antibodies directed against $\mathrm{gB}$ and

gD significantly decreases mortality even 48 hours after

the Initiation of infection. These data suggest a role

for combination therapy in individuals with HSV
infections of the CBS. 